\title{
Characterization and Development of Osmotolerant Caldicellulosiruptor Strains Targeting Enhanced Hydrogen Production from Lignocellulosic Hydrolysates
}

\section{Eoin Byrne}

Lund University: Lunds Universitet

Johanna Björkmalm

RISE Research Institutes of Sweden AB

James Bostick

Lunds Universitet

Krishnan Sreenivas

Lunds Universitet

Karin Willquist

RISE Research Institutes of Sweden AB

Ed Van Niel ( $\nabla$ ed.van_niel@tmb.Ith.se )

Lund University https://orcid.org/0000-0003-2103-6013

\section{Research}

Keywords: Osmolarity, Caldicellulosiruptor, biohydrogen, kinetic model, adaptive laboratory evolution

Posted Date: December 7th, 2020

DOl: https://doi.org/10.21203/rs.3.rs-118276/v1

License: (c) (i) This work is licensed under a Creative Commons Attribution 4.0 International License.

Read Full License 
1 Characterization and development of 2 osmotolerant Caldicellulosiruptor strains 3 targeting enhanced hydrogen production 4 from lignocellulosic hydrolysates

5

6

7

8

9

10 Eoin Byrne ${ }^{1}$, Johanna Björkmalm ${ }^{1,2}$, James P. Bostick ${ }^{1}$, 11 Krishnan Sreenivas ${ }^{1}$, Karin Willquist ${ }^{2}$, Ed W.J. van Niel $^{1}$

12

13

14

15

16

17

18

19

20

21

22

23

24

25

26

27

28

29

30

${ }^{1}$ Division of Applied Microbiology, Lund University, PO Box 124, 22100 Lund, Sweden

${ }^{2}$ RISE, Ideon Science Park, Building Beta 2 3v Scheelevägen 17, SE-22370 Lund

\section{Keywords}

Osmolarity, Caldicellulosiruptor, biohydrogen, kinetic model, adaptive laboratory evolution 


\section{Abstract}

$\underline{\text { Background }}$

33 The members of the genus Caldicellulosiruptor have the potential for future integration into a biorefinery system due to their capacity to generate hydrogen close to the theoretical limit of $4 \mathrm{~mol} \mathrm{H}_{2} / \mathrm{mol}$ hexose, use a wide range of sugars and can grow on numerous lignocellulose hydrolysates. However, members of this genus are unable to survive in high osmolarity conditions, limiting their ability to grow on more concentrated hydrolysates, thus impeding their industrial applicability. In this study five members of this genus, $C$. owensensis, C. kronotskyensis, C. bescii, C. acetigenus and C. kristjanssonii, were developed to tolerate higher osmolarities through an adaptive laboratory evolution (ALE) process. The developed strain C. owensensis $\mathrm{CO} 80$ was further studied accompanied by the development of a kinetic model based on Monod kinetics.

\section{$44 \quad \underline{\text { Results }}$}

Osmotolerant strains of Caldicellulosiruptor were obtained with $C$. owensensis adapted to grow up to $80 \mathrm{~g} / 1$ glucose; other strains in particular C. kristjanssonii demonstrated a greater restriction to adaptation. C. owensensis $\mathrm{CO} 80$ was further studied and demonstrated the ability to grow in glucose concentrations up to 80 $\mathrm{g} / \mathrm{l}$ glucose but with reduced volumetric hydrogen productivities $\left(\mathrm{Q}_{\mathrm{H} 2}\right)$ and incomplete sugar conversion at elevated glucose concentrations. In addition, the carbon yield decreased with elevated concentrations of glucose. The ability of $C$. owensensis $\mathrm{CO} 80$ to grow in high glucose concentrations was further described with a kinetic growth model, which revealed that the critical osmolarity of the cells increased fourfold when cultivated at higher osmolarity. When co-cultured with the osmotolerant strain $C$. saccharolyticus G5 at a hydraulic retention time

56 (HRT) of $20 \mathrm{~h}$, C. owensensis constituted only $0.09-1.58 \%$ of the population in 57 suspension. 
The adaptation of members of the Caldicellulosiruptor genus to higher osmolarity established that the ability to develop improved strains via ALE is species dependent, with $C$. owensensis adapted to grow on $80 \mathrm{~g} / \mathrm{l}$, whereas $C$. kristjanssonii could only be adapted to $30 \mathrm{~g} / \mathrm{l}$ glucose. Although, C. owensensis CO80 was adapted to a higher osmolarity medium, the strain demonstrated reduced $\mathrm{Q}_{\mathrm{H} 2}$ with elevated glucose concentrations. This would indicate that while ALE permits adaptation to elevated osmolarities, this approach does not result in improved fermentation performances at these higher osmolarities. Moreover, the observation that planktonic culture of $\mathrm{CO} 80$ was outcompeted by an osmotolerant strain of $C$. saccharolyticus, when co-cultivated in continuous mode, indicates that the robustness of strain CO80 should be improved for industrial application.

\section{Background}

The current reliance on fossil fuels as the main source of global energy production is not sustainable.. Biofuels derived from renewable sources are an extensively researched alternative for the production of energy, however, it is of great importance these fuels do not compete with food production in terms of land usage (Sims et al., 2008). Within the European Union, current legislation restricts dedicated biofuel production to $7 \%$ of total land use (European Parliament and Council, 2015). Lignocellulose is a potential substrate for biofuel production due to its wide availability with 1-5 billion tonnes yielded annually (Claassen et al., 1999). Currently, over 40 million tonnes of this material is generated as a by-product of agriculture and forestry (Sanderson, 2011), and is ideally suited for biofuel production as lignocellulose obtained from waste streams does not affect land usage or food production. 
Biologically derived hydrogen (biohydrogen) has the potential to be an alternative energy carrier as it can be produced from renewable sources such as lignocellulose and only generates water vapor as a by-product when used as a fuel (Azwar et al., 2014). Caldicellulosiruptor is a genus of thermophilic hydrogen producing bacteria capable of yielding hydrogen close to the maximum stoichiometric yield of $4 \mathrm{~mol} \mathrm{H}_{2} / \mathrm{mol}$ hexose (Rainey et al., 1994; Schleifer, 2009). Notably, most members of this genus can metabolize a wide range of carbon sources including an array of mono-, oligo- and polysaccharides (Schleifer, 2009). Species such as C. saccharolyticus and C. owensensis display the capacity to simultaneously consume hexoses and pentoses without catabolite repression and therefore is beneficial to an industrial process as both the cellulose and hemicellulose fractions of lignocellulose can be consumed together (Björkmalm et al., 2018; VanFossen et al., 2009; Zeidan \& van Niel, 2010). Additionally, Caldicellulosiruptor has been previously utilized to generate hydrogen from a variety of lignocellulosic material (Byrne et al., 2018; de Vrije et al., 2009; Pawar et al., 2013).

101 Although a promising candidate for industrial biohydrogen production,

102 Caldicellulosiruptor experiences several key limitations including the ability to

103 grow in high osmotic conditions (Byrne et al., 2018; Ljunggren et al., 2011;

104 Pawar et al., 2013). In its natural environment Caldicellulosiruptor does not 105 experience a high degree of osmotic stress and has thus adapted to low 106 osmolarities, maximally of 0.4 to $0.425 \mathrm{Osmol} / \mathrm{L}$, with a critical osmolarity of 1070.27 to 0.29 Osmol/L. This osmo-sensitivity limits the industrial potential of 108 Caldicellulosiruptor as it precludes cultivation in concentrated lignocellulose 109 hydrolysates. Concentrated hydrolysates are essential for environmentally 110 efficient production of thermophilic $\mathrm{H}_{2}$ as higher substrate concentrations reduce 111 the requirement for water addition and energy input for heating (Byrne et al., 112 2018; Foglia et al., 2010; Ljunggren \& Zacchi, 2010). 
113 Mathematical modeling is a powerful tool to assess how the key physical and 114 biological phenomena in a process function. Inhibition arising from 115 osmosensitivity can be one such phenomenon and is further addressed in this 116 paper. This modeling of quantitative description of substrate inhibition and 117 inhibition due to a high degree of osmotic stress have previously been studied 118 using different types of growth kinetic equations (Azimian et al., 2019; Ciranna 119 et al., 2014; Dötsch et al., 2008; van Niel et al., 2003). A non-competitive 120 equation is commonly used to describe growth inhibition due to substrate or 121 soluble end products (Ciranna et al., 2014; van Niel et al., 2003).

122 One way to improve osmotolerance in microorganisms is through targeting genes 123 involved in responses to increased osmotic pressure through metabolic 124 engineering and has become an intensive research approach ( $\mathrm{Lv}$ et al 2020). 125 Recently, C. bescii was investigated to identify its response mechanism to higher 126 osmolarities, which then can be targeted by directed engineering (Sander et al., 127 2020). Alternatively, when genetic engineering tools are missing strain 128 improvement can be accomplished through a process known as adaptive 129 laboratory evolution (ALE). In this process an organism is repeatedly sub130 cultivated under defined conditions enabling a controlled adaptation to these 131 conditions and hence a favorable phenotype change can develop (Dragosits \& 132 Mattanovich, 2013). We have applied this successively with C. saccharolyticus 133 (Pawar 2014), and here we describe the development of several osmotolerant 134 strains of other Caldicellulosiruptor species, i.e., $C$. owensensis, $C$. 135 kronotsyensis, C. bescii, C. acetigenus and C. kristjanssonii through sequential $136 \mathrm{ALE}$ at incrementally increasing glucose concentrations. The adapted 137 osmotolerant strain C. owensensis (CO80) was cultivated in controlled batch and 138 exposed to a high concentration of glucose, up to $80 \mathrm{~g} / \mathrm{L}$. To quantify the success 139 of strain development, this process was modelled using a growth kinetic equation 140 based on Monod with a set of inhibition equations. Finally, C. owensensis CO80 141 was further analyzed in co-cultures with the osmotolerant strain G5 of $C$. 
142 saccharolyticus (Pawar 2014), on defined media and lignocellulosic hydrolysate

143 of which the data have been published elsewhere (Byrne et al. (2018).

\section{Results}

\section{Strain development}

146 To assess the ability of different strains of the Caldicellulosiruptor genus to adapt

147 to higher osmolarity and to select an osmotolerant strain for further development,

148 ALE was undertaken on five species of Caldicellulosiruptor. The respective 149 increase in viability at higher osmolarity was determined during sequential 150 batches, whereby increased sugar concentration was used as a selective pressure.

151 The ALE design replicated a previous study that achieved the selection of a $C$. 152 saccharolyticus strain with the capacity to grow on $100 \mathrm{~g} / \mathrm{L}$ glucose (Pawar, 153 2014). Out of the five selected strains, only C. owensensis was successfully 154 adapted to grow on a glucose concentration of $80 \mathrm{~g} / \mathrm{L}$ (Figure 1) over the course 155 of approximately 250 generations. The adaptation of $C$. kronotskyensis 156 demonstrated viability in solutions up to $60 \mathrm{~g} / \mathrm{L}$ glucose but at $70 \mathrm{~g} / \mathrm{L}$ it did not 157 reach the threshold value of $\mathrm{OD}_{620} 0.4$ and therefore was not selected for further 158 analysis. In contrast, the adaptation strategy of $C$. kristjanssonii, $C$. bescii and $C$. 159 acetigenus was quite restrictive. Even with repeated cultivation at lower sugar 160 concentrations a loss of viability occurred. C. kristjanssonii was particularly 161 sensitive to adaptation and exhibited poor viability in glucose concentrations as 162 low as $20 \mathrm{~g} / \mathrm{L}$. Overall, C. owensensis had a greater ability to adapt to higher 163 osmolarity medium than any other strain. Adaptation of C. owensensis to $100 \mathrm{~g} / \mathrm{L}$ 164 glucose was attempted, however, strains adapted to 90 and $100 \mathrm{~g} / \mathrm{L}$ displayed 165 poor growth and a loss of viability after several rounds of cultivation. Therefore, 166 the $C$. owensensis strain adapted to $80 \mathrm{~g} / \mathrm{L}$ glucose $(\mathrm{CO} 80)$ was selected for 167 further analysis. 
168 Adaptation of bacterial cells to higher osmolalities is usually related to 169 intracellular accumulation of compatible solutes and therefore a focused 170 bioinformatics study was performed (Kempf \& Bremer, 1998). However, similar

171 to C. saccharolyticus (Willquist et al., 2009), C. owensensis lacks key metabolic 172 pathways for the synthesis of compatible solutes for high osmotic conditions. $C$. 173 owensensis lacks synthetic pathways for the osmoprotectants glycine betaine, 174 ectoine and trehalose. C. owensensis also lacks pathways associated with the 175 synthesis of compatible solutes in thermophiles such as the di-myo-inositol 176 phosphate pathway (Gonçalves et al., 2012; Martins \& Santos, 1995) and the 177 synthesis pathway for 2-O-( $(\beta)$-mannosylglycerate as found in Thermus 178 thermophilus (Nunes et al., 1995). In addition, no homology between the $C$. 179 owensensis genome and 2-(O- $\beta$-d-mannosyl)-di-myo-inositol-1,3'-phosphate 180 synthase (TM0359) in Thermotoga maritima (Rodrigues et al., 2009) could be 181 found. However, C. owensensis can produce glutamate and has the full synthetic 182 pathway of proline.

184 Quantitative analysis of CO80 growth at higher sugar concentrations

185 C. owensensis CO80 was successfully cultivated on 10,30 and $80 \mathrm{~g} / \mathrm{L}$ using a 186 controlled batch reactor. The trends of sugar consumption, growth and product 187 formation in these cultures on these different sugar concentrations were 188 monitored (Figures 2-4).

189 The behavior of strain CO80 at increasing glucose concentrations was quantified 190 using dynamic simulations. In these simulations, the model and parameters 191 derived from the wild-type strain of $C$. saccharolyticus were used as a 192 benchmark (Ljunggren et al., 2011). However, this model was not able to 193 describe the experimental data. One reason for this is that the benchmark value of 194 the parameter OSM $_{\text {crit }}$ taken from Ljunggren et al. (2011) was set too low for the 
higher glucose concentrations. In addition, the benchmark values for parameters

196 of the maximum specific growth rate $\left(\mu_{\max }\right)$, affinity constant for glucose $\left(\mathrm{K}_{\mathrm{s}}\right)$ and

197 the rate of death $\left(\mathrm{r}_{\mathrm{cd}}\right)$ required alteration since the growth was slower and the cell

198 death rate was higher than predicted by the original model.

199

Table 1. Parameters calibrated to experimental data of $C$. owensensis cultures in comparison to the benchmark parameter values of $C$. saccharolyticus cultures from Ljunggren et al (2011).

\begin{tabular}{|c|c|c|c|c|c|}
\hline Parameter & $\begin{array}{c}\text { Benchmark } \\
\text { values } \\
\text { Ljunggren et al. } \\
\text { (2011) }\end{array}$ & $10 \mathrm{~g} / \mathrm{L}$ & $30 \mathrm{~g} / \mathrm{L}^{1}$ & $30 \mathrm{~g} / \mathrm{L}^{2}$ & $80 \mathrm{~g} / \mathrm{L}$ \\
\hline$\mu_{\max }\left(h^{-1}\right)$ & 0.28 & $0.33 \pm 0$ & $0.31 \pm 0.082$ & $0.31 \pm 0.082$ & $0.29 \pm 0.02$ \\
\hline \multirow[t]{2}{*}{$\mathrm{K}_{\mathrm{S}}(\mathrm{mol} / \mathrm{L})$} & $4.8 \cdot 10^{-5}$ & $4.8 \cdot 10^{-3}$ & $9.8 \cdot 10^{-2} \pm$ & $4.8 \cdot 10^{-5,5}$ & $0.49 \pm 0.064$ \\
\hline & & & $1.5 \cdot 10^{-4}$ & & \\
\hline $\begin{array}{l}\mathrm{OSM}_{\text {crit }} \\
(\mathrm{mol} / \mathrm{L})\end{array}$ & 0.28 & $0.23 \pm 0.0002$ & $0.39 \pm 0.002$ & $0.39 \pm 0.002$ & $0.78 \pm 0.024$ \\
\hline $\mathbf{r}_{\mathrm{cd}}\left(\mathbf{h}^{-1}\right)$ & 0.014 & $0.031 \pm 0.0001$ & $0.031 \pm 0.0065$ & $\begin{array}{l}0.020 \pm \\
0.00015\end{array}$ & $0.031^{3}$ \\
\hline $\begin{array}{c}\mathbf{Y}_{\mathrm{S}, \mathrm{H} 2} \\
(\mathbf{m o l} / \mathbf{m o l})\end{array}$ & 4.77 & $3.5 \pm 0.38$ & $3.5 \pm 0.12$ & $3.5 \pm 0.12$ & $2.56^{3}$ \\
\hline $\begin{array}{c}\mathbf{Y}_{\mathrm{S}, \mathrm{X}} \\
(\mathrm{cmol} / \mathbf{m o l})\end{array}$ & 4.78 & $0.79^{4}$ & $0.80^{4}$ & $0.80^{4}$ & $0.72^{3}$ \\
\hline $\mathbf{n}_{\mathrm{H} 2}$ & 4.5 & $5.37 \pm 0.00005$ & $5.37^{3}$ & $5.37^{3}$ & $4.5^{5}$ \\
\hline $\mathbf{n}_{\mu .}$ & 4.68 & $4.68^{5}$ & $4.68^{5}$ & $4.68^{5}$ & $4.68^{5}$ \\
\hline
\end{tabular}

204

205

206

207

208

209

210

211

212

213 Therefore, the model was calibrated with all data from the duplicates or 214 triplicates of the three batch experiments supplemented with $10 \mathrm{~g} / \mathrm{L}, 30 \mathrm{~g} / \mathrm{L}$ and 
$21580 \mathrm{~g} / \mathrm{L}$ glucose. The calibrated parameters $\mu_{\max }, \mathrm{OSM}_{\text {crit }}$ and $\mathrm{K}_{\mathrm{S}}$, together with

216 additional parameters are summarized in Table 1. Comparison between the

217 model and the experimental results are graphically shown in Figure 2-4.

218 The maximum hydrogen productivity from the experimental data was $10.55 \pm$ $2190.04,11.45 \pm 0.00$ and $3.35 \pm 0.00 \mathrm{mmol} / \mathrm{L} / \mathrm{h}$ for 10,30 and $80 \mathrm{~g} / \mathrm{L}$ sugar, 220 respectively. This observation at 10 and $30 \mathrm{~g} / \mathrm{L}$ is comparable to $15 \mathrm{mmol} / \mathrm{L} / \mathrm{h}$ 221 described in wild-type $C$. owensensis grown on $10 \mathrm{~g} / \mathrm{L}$ glucose supplemented 222 with $1 \mathrm{~g} / \mathrm{L}$ yeast extract (Zeidan \& van Niel, 2010). The model underestimated 223 the hydrogen productivity slightly in the case of 10 and $30 \mathrm{~g} / \mathrm{L}$ but overestimated 224 productivity compared to experimental data of $80 \mathrm{~g} / \mathrm{L}$ cultures. Similar 225 overestimation was observed with respect to the cell growth on $80 \mathrm{~g} / \mathrm{L}$. 226 Nevertheless, the model was able to predict the experimental data adequately.

227 The accuracy of the model in describing experimental data was assessed (Table 228 2. The $\mathrm{R}^{2}$ values describes how well the model could predict the trend over time 229 and the curve slope values of the linear regression (i.e., $\mathrm{k}$ in $\mathrm{y}=\mathrm{k} \cdot \mathrm{x}$ ) are 230 indicating over- or underestimations. For a perfect fit they should both be 1 . With 231 respect to most variables, the prediction error was less than $30 \%$ indicating good 232 accuracy. The model was also able to accurately predict the trend of the assessed 233 variables with a $\mathrm{R}^{2}$ value close to 1 in all cases. However, analysis revealed the 234 overestimation of cell growth as well as acetate and lactate production of the 235 cultures on $30 \mathrm{~g} / \mathrm{L}$ glucose (Table 2 ).

237 Inhibition kinetics

238 The glucose concentration portrayed a linear relationship with the apparent half239 saturation constant $\left(\mathrm{K}_{\mathrm{S}}\right)$ and critical osmolarity $\left(\mathrm{OSM}_{\text {crit }}\right)$ (Figure 5). The apparent $240 \mathrm{~K}_{\mathrm{S}}$ increased with the elevating glucose concentration reaching a value four 
Table 2. $\mathrm{R}^{2}$ values and curve slope values to describe the fit between average experimental data and simulated data from the models at the same time points.

\begin{tabular}{|c|c|c|c|c|c|c|c|}
\hline $\begin{array}{l}\mathbf{R}^{2} \\
\text { values/curve } \\
\text { slope values } \\
(\mathbf{k}) \\
\end{array}$ & \multicolumn{2}{|c|}{$10 \mathrm{~g} / \mathrm{L}$} & \multicolumn{3}{|c|}{$30 \mathrm{~g} / \mathrm{L}$} & \multicolumn{2}{|c|}{$80 \mathrm{~g} / \mathrm{L}$} \\
\hline $\begin{array}{l}\text { State } \\
\text { variable }\end{array}$ & Model & $\begin{array}{c}\mathrm{K}_{\mathrm{S}} \\
\text { model }\end{array}$ & $\begin{array}{c}\text { Model } \\
1\end{array}$ & $\begin{array}{c}\text { Model } \\
2\end{array}$ & $\begin{array}{c}\mathrm{K}_{\mathrm{S}} \\
\text { model }\end{array}$ & Model & $\begin{array}{c}\mathrm{KS} \\
\text { model }\end{array}$ \\
\hline Glu & $\begin{array}{c}0.94 / \\
0.95\end{array}$ & $\begin{array}{c}0.67 / \\
0.93\end{array}$ & $\begin{array}{c}0.91 / \\
0.96\end{array}$ & $\begin{array}{l}0.89 / \\
0.95\end{array}$ & $\begin{array}{c}0.83 / \\
1.0\end{array}$ & $\begin{array}{c}0.87 / \\
0.99\end{array}$ & $\begin{array}{c}0.85 / \\
0.98\end{array}$ \\
\hline Biomass & $\begin{array}{l}0.82 / \\
0.96\end{array}$ & $\begin{array}{c}0.77 / \\
1.0\end{array}$ & $\begin{array}{c}0.50 / \\
6.0\end{array}$ & $\begin{array}{c}0.28 / \\
6.8\end{array}$ & $\begin{array}{c}0.82 / \\
4.2\end{array}$ & $\begin{array}{c}0.96 / \\
0.43\end{array}$ & $\begin{array}{c}0.94 / \\
0.43\end{array}$ \\
\hline Acetate & $\begin{array}{l}0.97 / \\
0.97\end{array}$ & $\begin{array}{c}0.75 / \\
1.2\end{array}$ & $\begin{array}{c}0.94 / \\
1.1\end{array}$ & $\begin{array}{c}0.96 / \\
1.1\end{array}$ & $\begin{array}{c}0.77 / \\
0.85\end{array}$ & $\begin{array}{c}0.99 / \\
0.54\end{array}$ & $\begin{array}{c}0.99 / \\
0.55\end{array}$ \\
\hline Lactate & $\begin{array}{c}0.95 / \\
1.4\end{array}$ & $\begin{array}{c}0.60 / \\
1.5\end{array}$ & $\begin{array}{c}0.97 / \\
2.0\end{array}$ & $\begin{array}{c}0.92 / \\
2.1\end{array}$ & $\begin{array}{c}0.83 / \\
1.4\end{array}$ & $\begin{array}{c}0.97 / \\
0.54\end{array}$ & $\begin{array}{l}0.98 / \\
0.54\end{array}$ \\
\hline $\begin{array}{l}\mathrm{H}_{2} \\
\text { accumulated }\end{array}$ & $\begin{array}{c}0.94 / \\
0.92\end{array}$ & $\begin{array}{c}0.51 / \\
1.1\end{array}$ & $\begin{array}{c}0.94 / \\
0.88\end{array}$ & $\begin{array}{l}0.96 / \\
0.98\end{array}$ & $\begin{array}{c}0.76 / \\
0.71\end{array}$ & $\begin{array}{c}0.99 / \\
0.72\end{array}$ & $\begin{array}{l}0.98 / \\
0.74\end{array}$ \\
\hline OSM & $\begin{array}{c}0.97 / \\
0.98\end{array}$ & $\begin{array}{c}0.57 / \\
1.0\end{array}$ & $\begin{array}{c}0.94 / \\
1.0\end{array}$ & $\begin{array}{c}0.97 / \\
1.0\end{array}$ & $\begin{array}{l}0.75 / \\
0.96\end{array}$ & $\begin{array}{l}0.91 / \\
0.40^{*}\end{array}$ & $\begin{array}{l}0.92 / \\
0.40 *\end{array}$ \\
\hline
\end{tabular}

*The linear regression does not intersect $(0,0)$.

248 orders of magnitude higher in the $80 \mathrm{~g} / \mathrm{L}$ glucose culture. As Sivakumar et al. 249 (1994) demonstrated, extraordinarily high $\mathrm{K}_{\mathrm{S}}$ values can be an indicator that the 250 growth kinetics applied is insufficient in describing the process due to substrate 251 inhibition, hence, an extended model was constructed. In the constructed " $\mathrm{K}_{\mathrm{S}^{-}}$ 252 model", the $\mathrm{K}_{\mathrm{S}}$ in the original model (Eq 7 in Material and Methods) was 253 replaced with the equation from the linear regression in Figure 5: 
255 where $\mu$ is the specific growth rate $\left(\mathrm{h}^{-1}\right), \mu_{\max }$ the maximum specific growth rate $256\left(\mathrm{~h}^{-1}\right)$, Glu is the glucose concentration $(\mathrm{mol} / \mathrm{L}), \mathrm{I}_{\mathrm{osm}}$ is the inhibition due to 257 osmolarity and $\mathrm{I}_{\mathrm{H} 2 \text {,aq }}$ is the inhibition due to aqueous hydrogen concentration. The 258 simulation using the " $\mathrm{K}_{\mathrm{S}}$-model" is illustrated in Figure 2-4 as a thin dashed line. 259 The $\mathrm{K}_{\mathrm{S}}$-model was well able to describe the experimental data (Table 2) for 30 $260 \mathrm{~g} / \mathrm{L}$ and $80 \mathrm{~g} / \mathrm{L}$ (Figure 3-4). However, for $10 \mathrm{~g} / \mathrm{L}$, the $\mathrm{K}_{\mathrm{S}}$-model could not 261 sufficiently describe the data (Table 2). This may be due to the greater glucose 262 consumption at $10 \mathrm{~g} / \mathrm{L}$ compared to the higher concentrations, thereby altering 263 the $\mathrm{K}_{\mathrm{S}}$-model equation to a greater extent than this model is dependent on the 264 glucose concentration.

265 The increase of $\mathrm{OSM}_{\text {crit }}$ with the sugar concentration (Figure 5) indicates that 266 strain CO80 adapts immediately when confronted with a raise in the osmolarity 267 or sugar concentration in the medium. This behavior became more apparent when 268 the inhibition kinetics of the fermentation was simulated in the different cases. 269 The model describes two different types of inhibition, i.e., inhibition by 270 osmolarity $\left(\mathrm{I}_{\mathrm{osm}}\right)$ and dissolved hydrogen concentration $\left(\mathrm{I}_{\mathrm{H} 2, \mathrm{aq}}\right)$ (Equation 6 and 271 7), which were simulated for all three glucose concentrations (Figure 6). A value 272 around 1 means no inhibition and a lower value means that the process is 273 inhibited. Figure 6 clearly shows that osmolarity is the crucial inhibition factor, 274 i.e., an $\mathrm{I}_{\mathrm{osm}}$ value $<1$. $\mathrm{I}_{\mathrm{H} 2 \text {,aq }}$ is of less importance as the simulated values were $2750.98<\mathrm{I}_{\mathrm{H} 2, \mathrm{aq}}<1$, which means almost no inhibition. Although, the $\mathrm{K}_{\mathrm{S}}$ model for 10 $276 \mathrm{~g} / \mathrm{L}$ gave values of $0.11<\mathrm{I}_{\mathrm{H} 2}, \mathrm{aq}<1$, this rather indicates that the model is not a 277 good fit to the experimental data at this glucose concentration, which confirms 278 what is depicted in Figure 2. Interestingly, the simulation of $\mathrm{I}_{\mathrm{osm}}$ illustrates that 279 although all fermentations was severely affected by osmolarity, strain CO80 280 grown on $80 \mathrm{~g} / \mathrm{L}$ glucose reached complete inhibition after $80 \mathrm{~h}$, whereas the 281 cultivation on $10 \mathrm{~g} / \mathrm{L}$ reached complete inhibition after $20 \mathrm{~h}$, although the initial 
282 osmolarity in this condition was lower. This indicates that although $C$.

283 owensensis $\mathrm{CO} 80$ is adapted to higher osmolarities it does not manifest the

284 phenotype unless it is stressed in an environment with a high osmolarity.

285 It should be noted that at high levels of sugar $(80 \mathrm{~g} / \mathrm{L})$, significant browning of 286 the media occurred likely due to the presence of Maillard products. This 287 observation could not be quantified and described by the model.

\section{$288 \quad$ Reproducibility of strain CO80}

289 The model was also used to illustrate the reproducibility of growth of strain 290 CO80 at increasing sugar concentrations. Three replicates were made for the 30 $291 \mathrm{~g} / \mathrm{L}$ experiments, as compared to two replicates for the $10 \mathrm{~g} / \mathrm{L}$ and $80 \mathrm{~g} / \mathrm{L}$ due to a 292 high degree of variation in one of the replicates. Several attempts at inoculating 293 strain CO80 to a culture medium containing $80 \mathrm{~g} / 1$ glucose failed, as it did not 294 grow when noticeable browning of the media due to Maillard reactions occurred. 295 As illustrated in Figure 3, one of the three replicates (30b) from the $30 \mathrm{~g} / \mathrm{L}$ 296 experiments differed with respect to hydrogen productivity and accumulation but 297 discrepancies could also be seen in the biomass growth. For this reason, a second 298 model (Model 2) with a slight difference in parameter values (Table 1) was 299 constructed for the $30 \mathrm{~g} / \mathrm{L}$ experiments. However, both Model 1 and Model 2 300 resulted in low $\mathrm{R}^{2}$ values and high curve slope values for the biomass (Table 2). 301 One of the three replicates could be simulated with respect to $\mathrm{OSM}_{\text {crit }}$ and 302 apparent saturation constant ( $\mathrm{K}_{\mathrm{S}}$; Figure 3$)$ whereas the other two could be fitted 303 better with the model where the parameters were much closer to those of the 10 $304 \mathrm{~g} / \mathrm{L}$ culture. This result might indicate that the adaptation was incomplete, 305 possibly due to the presence of subpopulations possessing different degrees of 306 adaptation to higher osmolarity (Peabody et al., 2016). 


\section{Evaluation of strain $\mathrm{CO80}$ in co-culture}

310 The results of the batch cultivations indicated that $C$. owensensis CO80 was

311 adapted to increased substrate concentrations but did not grow optimally at these

312 conditions. A further attempt has been made to improve the performance of this

313 strain by co-cultivation with the osmotolerant $C$. saccharolyticus strain G5 in

314 defined media and wheat straw hydrolysate, of which the data were published

315 elsewhere (Byrne et al., 2018). Overall, the co-cultures on wheat straw

316 hydrolysate displayed better performance, such as higher $\mathrm{Q}_{\mathrm{H} 2}$ and sugar

317 consumption rates, than on the defined media that contained a sugar composition

318 corresponding to the wheat straw hydrolysate (Table 3).

Table 3. Volumetric productivity of of co-cultures of C. owensensis CO80 and C. saccharolyticus G5.

\begin{tabular}{|c|c|c|c|}
\hline & $\begin{array}{c}\text { Wheat } \\
\text { straw } \\
\text { hydrolysat } \\
\text { e with EB- } \\
1\end{array}$ & $\begin{array}{c}\text { Defined medium } \\
\text { with EB-1 }\end{array}$ & $\begin{array}{c}\text { Defined medium } \\
\text { Modified DSM } 640\end{array}$ \\
\hline $\mathrm{Q}_{\text {glucose }}$ & $1.88 \pm 0.02$ & $0.18 \pm 0.16$ & $0.09 \pm 0.13$ \\
\hline$Q_{\text {xylose }}$ & $2.64 \pm 0.39$ & $1.26 \pm 0.07$ & $1.49 \pm 0.25$ \\
\hline Q arabinose & $0.18 \pm 0.00$ & $0.20 \pm 0.00$ & $0.16 \pm 0.00$ \\
\hline Qacetate & $4.74 \pm 0.00$ & $2.37 \pm 0.37$ & $2.63 \pm 0.38$ \\
\hline $\mathrm{Q}_{\mathrm{H} 2}$ & $6.71 \pm 0.06$ & $2.47 \pm 0.55$ & $3.71 \pm 0.42$ \\
\hline
\end{tabular}

323

324

325

326

Data adapted from Byrne et al. (2018) 
Table 4. Population distribution of $C$. owensensis strain $\mathrm{C} 80$ and $C$. saccharolyticus G5 in continuous cultures.

\begin{tabular}{ccc}
\hline Proportion & Strain G5 & Strain C80 \\
\hline $\begin{array}{c}\text { Wheat straw } \\
\text { hydrolysate }\end{array}$ & $99.76 \pm 0.43 \%$ & $0.24 \pm 0.43 \%$ \\
Defined medium EB-1 & $99.91 \pm 0.01 \%$ & $0.09 \pm 0.01 \%$ \\
Defined medium DSM & $98.45 \pm 3.06 \%$ & $1.58 \pm 3.17 \%$ \\
640 & & \\
\hline
\end{tabular}

333 The population dynamics of co-cultures were analyzed to determine the stability 334 of the co-cultures. As illustrated in Table 4, only a minute proportion of the co-

335 culture consisted of $C$. owensensis $\mathrm{CO} 80$ in each case, thus $C$. saccharolyticus

336 G5 dominated. However, a brief interruption of $\mathrm{pH}$ control during the co-culture

337 on modified DSM 640 resulted in the population of CO80 exceeding $85 \%$ of the 338 total population before returning to less than $1 \%$ after 2 volume changes. 339 Although, low population numbers of planktonic CO80 were observed, a large 340 quantity of biofilm occurred in all continuous cultivations particularly at the gas341 liquid interface.

\section{Discussion}

344 In this study we successfully implemented ALE as strain development technique 345 to improve the survival of $C$. owensensis in osmolarity-induced stress conditions. 
346 Next to C. saccharolyticus (Pawar, 2014), this is the second Caldicellulosiruptor

347 species to withstand higher osmolarities via adaptation. C. owensensis was 348 successfully adapted to survive in $80 \mathrm{~g} / \mathrm{L}$ glucose. However, not all 349 Caldicellulosiruptor strains were as easily adaptable in our study. There were 350 significant restrictions in the adaptation of $C$. bescii, C. acetigenus and $C$. 351 kristjanssonii to higher sugar concentrations. C. kristjanssonii displayed a 352 particular resistance to adaptation to higher osmolarities in glucose 353 concentrations with a loss of viability above $30 \mathrm{~g} / \mathrm{l}$. Previously, a transcriptional 354 analysis demonstrated that adaptation in C. saccharolyticus was a result of 355 increased transposon activity as well as upregulation of proteins related to sugar 356 transport (Pawar 2014). A recent study, (Sander et al., 2020), succeeded in 357 developing two $C$. bescii strains possessing higher osmotolerance through genetic 358 engineering. Analyses of these strains phenotypes resulted in that enhanced 359 tolerance was accomplished through deletion of the FapR, a negative regulator of 360 the fatty acid synthesis. Their analysis further hinted that mutations in regions of 361 the genome of as yet unknown function, also increased osmotolerance, which 362 demands validation. In short, evolvement of higher tolerance to osmotic potential 363 may depend on expression of various (combinations of) genes and may even be 364 species or strain dependent.

365 Although ALE increased osmotolerance, C. owensensis CO80 exhibits 366 incomplete glucose consumption at elevated concentrations. This phenomenon 367 has been previously observed in wild-type C. saccharolyticus (Pawar 2014). In 368 addition, when cultivated on $80 \mathrm{~g} / \mathrm{L}$ glucose, a significantly reduced volumetric 369 hydrogen productivity was obtained compared to 10 and $30 \mathrm{~g} / \mathrm{L}$. Additionally, 370 glucose uptake capacity was negatively affected, indicating that although $C$. 371 owensensis is capable of surviving at $80 \mathrm{~g} / \mathrm{L}$, a significant loss of performance is 372 observed. 
373 The model was shown to be a useful tool to quantify the experimental 374 observations. For instance, a high value of the $\mathrm{OSM}_{\text {crit }}$ parameter in the model 375 indicated a higher tolerance to osmolarity, but the maximum capacity appeared to 376 adjust with the osmolarity of the medium. In other words, the osmotolerance 377 phenotype shifted in unison with the osmotic pressure of the environment, 378 implicating the involvement of an active physiological mechanism. However, the 379 presence of substrate inhibition, mainly in cultures at $30 \mathrm{~g} / \mathrm{L}$ and $80 \mathrm{~g} / \mathrm{L}$ glucose, 380 may complicate further kinetic analysis of this phenomenon. Due to this 381 inhibition, the apparent $\mathrm{K}_{\mathrm{S}}$ value of the culture with $80 \mathrm{~g} / \mathrm{L}$ glucose appeared to 382 be four orders of magnitude higher than that of the cells in the culture of $10 \mathrm{~g} / \mathrm{L}$ 383 glucose (Equation 7) and in previous studies (Ciranna et al., 2014; Ljunggren et 384 al., 2011; van Niel et al., 2003). This equation is adequate at low sugar 385 concentrations, but it might not be sufficient to describe a fermentation with 386 higher sugar concentrations. The calibrated $\mathrm{K}_{\mathrm{S}}$ for the $80 \mathrm{~g} / \mathrm{L}$ case is an "apparent $387 \mathrm{~K}_{\mathrm{S}}$ " which most probably constitutes of the "real $\mathrm{K}_{\mathrm{S}}$ " multiplied by an inhibition 388 factor. To counteract such a high $\mathrm{K}_{\mathrm{S}}$ value, a second model, where $\mathrm{K}_{\mathrm{S}}$ was a 389 function of glucose, was used instead (Equation 1). This model gave a similar fit 390 to the data for the $30 \mathrm{~g} / \mathrm{L}$ and $80 \mathrm{~g} / \mathrm{L}$ cultures. Furthermore, the inhibition due to 391 osmolarity was of a higher significance than inhibition by the aqueous hydrogen 392 concentration as analyzed in Figure 6.

393 When calibrating the parameters in the model to get a good fit to the 394 experimental data, an initial start value of the parameter needs to be 395 guesstimated. These values are of great importance for the end result as a poorly 396 chosen initial value could result in a local minimum in the parameter estimation 397 procedure, leading to a bad fit of the model to the experimental data and a faulty 398 estimated parameter. To counteract this, the start values were initially chosen in 399 proximity to the benchmark value from Ljunggren et al. (2011). When these 400 values did not give the right fit to the experimental data, several new initial start 401 values were tested as input in the lsqcurvefit function in MATLAB. 
402 The reduction in $\mathrm{Q}_{\mathrm{H} 2}$ observed in batch fermentations is consistent with the data

403 derived from Byrne et al. (2018) establishing that utilizing osmotolerant strains

404 facilitated use of more concentrated hydrolysates albeit at the expense of $\mathrm{Q}_{\mathrm{H} 2}$. In

405 that study the $\mathrm{Q}_{\mathrm{H} 2}$ of the co-culture $(6.71 \pm 0.06 \mathrm{mmol} / \mathrm{L} / \mathrm{h})$ was lower than that

406 observed in pure culture of the wild-type $C$. saccharolyticus grown on

407 approximately threefold lower concentrated WSH containing $11 \mathrm{~g} / \mathrm{L}$

408 monosaccharides $(8.69 \mathrm{mmol} / \mathrm{L} / \mathrm{h})$ (Pawar et al., 2013). However, the $\mathrm{Q}_{\mathrm{H} 2}$

409 obtained with the defined DSM 640 medium was similar to that of wild-type $C$.

410 saccharolyticus $(4.2 \mathrm{mmol} / \mathrm{L} / \mathrm{h})$ (de Vrije et al., 2007). Furthermore, the co-

411 culture grown on WSH displayed a higher $\mathrm{Q}_{\mathrm{H} 2}$ when cultivated on wheat straw

412 hydrolysate than on a defined medium. This confirms previous observations that

413 Caldicellulosiruptor possesses a higher $\mathrm{Q}_{\mathrm{H} 2}$ when cultivated on wheat straw

414 hydrolysate than on pure sugar (Pawar et al., 2013). This may be due to the

415 presence of additional nutrients and/or oligosaccharides found in the wheat straw

416 compared to that of the defined medium. The reduction of $\mathrm{Q}_{\mathrm{H} 2}$ compared to the

417 wild-type C. saccharolyticus could be due to the presence of higher

418 concentrations of inhibitory compounds that may reduce hydrogen productivity.

419 C. saccharolyticus is sensitive to HMF and furfural concentrations above 1 and 2

420 g/L, respectively (de Vrije et al., 2009; Panagiotopoulos et al., 2010). Even

421 though higher hydrolysate concentrations were used in the present study, only

422 trace amounts of HMF and furfural were detected. The presence of, yet unknown,

423 compounds in the hydrolysate could have resulted in the inhibition of

424 Caldicellulosiruptor. Furthermore, higher concentrations of sugar intensified the

425 occurrence of Maillard reactions, to which Caldicellulosiruptor species are very

426 sensitive. A concentration of $80 \mathrm{~g} / \mathrm{l}$ glucose led to significant browning of the

427 cultivation media and resulted in failure of growth when the coloring arose

428 before inoculation and was presumably also responsible for inconsistencies

429 during cultivation at $30 \mathrm{~g} / \mathrm{L}$. Maillard products are known to inhibit the growth of

430 other thermophilic bacterial species such as Thermotoga and 
431 Thermoanaerobacter (de Vrije et al., 2009; Tomás et al., 2013). The presence of

432 Maillard-based products will reduce the efficiency of any large-scale

433 fermentation. One obvious choice for mitigating such reactions would be the

434 omission of cysteine from the cultivation medium or by maintaining a low

435 background sugar concentration in the culture through utilizing fed-batch or

436 continuous cultures as modes of operation.

437 Additionally, the co-cultivation of C. owensensis CO80 and C. saccharolyticus

$438 G 5$ resulted in a predominantly $C$. saccharolyticus $G 5$ population, with detection

439 of only small quantities of $C$. owensensis CO80. Although, this could indicate

440 cell mass washout of planktonic C. owensensis CO80. However, a large quantity

441 of biofilm was observed in the bioreactors after termination of each cultivation.

442 Due to that $C$. owensensis is known for its ability to form biofilm (Peintner et al.,

443 2010) might point that $C$. owensensis CO80 remained significantly present in the

444 fermentations in immobilized form.

\section{Conclusions}

446 The adaptation of Caldicellulosiruptor to higher osmotic conditions through ALE

447 permitted survival at higher sugar concentrations, however, at the cost of $\mathrm{Q}_{\mathrm{H} 2}$.

448 Implementation of co-cultures of C. owensensis CO80 and C. saccharolyticus G5

449 facilitated cultivation of this genus in higher hydrolysate concentrations than

450 previously reported, but even here reduced $\mathrm{Q}_{\mathrm{H} 2}$ were observed compared to wild-

451 type C. saccharolyticus on dilute hydrolysate. It stands to reason that ALE leads

452 to adaptation to the stress parameter to which its exposed, albeit at the expense of

453 other desired traits. Therefore, a combination of ALE and metabolic engineering

454 as applied in a Design, Build, Test and Learn cycle (Sandberg et al 2019) is a

455 better strategy to construct the desired phenotype of a hydrogen cell factory. The

456 kinetic models developed herein, were able to predict the behavior of growth of 
457 CO80 when exposed to 10 and $30 \mathrm{~g} / \mathrm{L}$ of glucose. The slight overestimation in 458 the models and the growth kinetics of cultures at $80 \mathrm{~g} / \mathrm{L}$ glucose illustrates that 459 this is the critical boundary beyond which this strain possesses no further 460 capacity for adaptation.

461 In contrast to C. saccharolyticus (Pawar et al., 2013), C. owensensis cannot be 462 cultivated without cysteine, as this species lacks the sulfur assimilation pathway 463 (Pawar \& van Niel, 2014). Therefore, co-cultivations of these two species in the 464 absence of cysteine, but with sulfate as the sole sulfur source, could be of 465 interest. In addition, co-cultivation of wild-type strains of $C$. saccharolyticus and 466 C. owensensis could also stimulate biofilm formation (Pawar et al., 2015). 467 However, this study demonstrated that C. saccharolyticus G5 strain completely 468 overtook the $C$. owensensis CO80 strain in the co-cultivations. Although this 469 observation can be considered discouraging, large quantities of biofilm occurred 470 indicating the presence of $C$. owensensis CO80. Therefore, alternative reactor 471 systems should be applied to enhance biofilm formation, thereby improving cell 472 mass retention that will contribute to higher $\mathrm{Q}_{\mathrm{H2}}$. The co-culture can possible be a 473 strategy to increase the robustness of the bioreactor performance since we 474 observed that CO80 took over at conditions when the bioreactor was acidified. 475 However, for industrial application the properties of CO80 to reach higher 476 hydrogen productivities need to be significantly improved.

\section{Material and Methods}

\section{$478 \quad$ Strains and cultivation medium}

479 The wild-type strains of Caldicellulosiruptor owensensis DSM 13100, 480 Caldicellulosiruptor kronotskyensis DSM 18902, Caldicellulosiruptor bescii 481 DSM 6725, Caldicellulosiruptor acetigenus DSM 7040 and Caldicellulosiruptor 482 kristjanssonii DSM 12137 were obtained from the Deutsche Sammlung von 
484 Subcultivations were conducted in $250 \mathrm{~mL}$ serum flasks with $50 \mathrm{~mL}$ modified 485 DSM 640 media (Willquist et al., 2009) with the addition of $50 \mathrm{mM}$ HEPES and

$48610 \mathrm{~g} / \mathrm{L}$ glucose, unless otherwise stated. A 1000x vitamin solution was prepared 487 as per Zeidan and van Niel (2010) and a modified SL-10 solution was prepared 488 described previously (Pawar \& van Niel, 2014).

\section{Adaptation of species to higher osmolarity}

490 Adaptation of $C$. owensensis, $C$. kronotsyensis, C. bescii, C. acetigenus and $C$.

491 kristjanssonii to higher osmolarity was performed through adaptive laboratory

492 evolution that initially involved repeated sub-cultivation of each strain in a

493 modified DSM 640 medium containing $10 \mathrm{~g} / \mathrm{L}$ of glucose. The glucose

494 concentration was increased in $10 \mathrm{~g} / \mathrm{L}$ increments when generation time for each

495 strain was less than $0.4 \mathrm{~h}^{-1}$ and OD was above 0.3 . This sequential increase of

496 glucose concentration was continued until no growth in higher glucose

497 concentrations was observed (Pawar, 2014).

\section{$498 \quad$ Fermentor set-up}

499 Batch cultivations were performed in a jacketed, 3-L fermentor equipped with an 500 ADI 1025 Bio-Console and ADI 1010 Bio-Controller (Applikon, Schiedam, The 501 Netherlands). A working volume of $1 \mathrm{~L}$ was used in all batch cultivations and the $502 \mathrm{pH}$ was maintained at $6.5 \pm 0.1$ by automatic titration with $4 \mathrm{M} \mathrm{NaOH}$. The 503 temperature was thermostatically kept at $70 \pm 1^{\circ} \mathrm{C}$. Stirring was maintained at $504250 \mathrm{rpm}$ and nitrogen was sparged through the medium at a rate of $6 \mathrm{~L} / \mathrm{h}$. A 505 water-cooled condenser was utilised $\left(4^{\circ} \mathrm{C}\right)$ to prevent the evaporation of the 506 medium. During each cultivation, samples were collected at regular intervals for 507 HPLC and to monitor optical density. The supernatant from each sample was 508 collected and stored at $-20^{\circ} \mathrm{C}$ for further quantification of sugars, organic acids, 509 and ethanol. Gas samples were collected from the headspace of the fermentor to 
510 quantify $\mathrm{H}_{2}$ and $\mathrm{CO}_{2}$. Analysis of osmotolerant $C$. owensensis $\mathrm{CO} 80$ was

511 performed using both batch cultivations with the addition of 10,30 and $80 \mathrm{~g} / \mathrm{L}$ of

512 glucose. Each of the batch cultivation was conducted in duplicate except for 30

$513 \mathrm{~g} / \mathrm{L}$ which was performed in triplicate. Co-culturing of $C$. owensensis $\mathrm{C} 80$ and $C$.

514 saccharolyticus G5 in continuous cultures were performed in a previous study

515 (Byrne et al 2018) at a dilution rate of $0.05 \mathrm{~h}^{-1}$. Three different media were used:

516 defined media (modified DSM 640 and EB-1) and wheat straw hydrolysate (for

517 media compositions see Byrne et al (2018)). Biomass samples were taken for

518 population dynamics during steady state situations.

\section{Analytical methods}

520 Optical density was determined using an Ultraspec 2100 pro spectrophotometer

521 (Amersham Biosciences) at $620 \mathrm{~nm}$.

522 Sugars and organic acids were detected using HPLC (Waters, Milford, MA,

523 USA). For the quantification of organic acids, and ethanol, a HPLC was used 524 equipped with an Aminex HPX-87H ion exchange column (Bio-Rad, Hercules, 525 USA) at $60{ }^{\circ} \mathrm{C}$ with $5 \mathrm{mM} \mathrm{H}_{2} \mathrm{SO}_{4}$ as mobile phase at a flow rate of $0.6 \mathrm{~mL} / \mathrm{min}$.

526 Glucose, xylose and arabinose quantification was conducted using a HPLC with 527 two Shodex SP-0810 Columns (Shodex, Japan) in series with water as a mobile 528 phase at a flow rate of $0.6 \mathrm{ml} / \mathrm{min}$.

$529 \mathrm{H}_{2}$ and $\mathrm{CO}_{2}$ concentrations were quantified with an Agilent 7890B Series GC 530 (Agilent GC 7890, Santa Clara, CA) equipped with a TCD detector and a 531 ShinCarbon ST 50/80 UM (2m x 1/16" x 1mm) column. Helium carrier gas was 532 employed, at a flow rate of $10 \mathrm{ml} / \mathrm{min}$. During operation, an initial oven 533 temperature of $80^{\circ} \mathrm{C}$ was maintained for 1 min followed by a temperature ramp 534 of $20^{\circ} \mathrm{C} / \mathrm{min}$ for $4 \mathrm{~min}$ with a subsequent $2 \mathrm{~min}$ hold time at $160^{\circ} \mathrm{C}$. 
537 DNA was extracted from $2 \mathrm{~mL}$ of frozen cell pellets -using the GeneJet Genomic

538 DNA purification kit (Thermofisher, Waltham, MA, USA). qPCR was carried 539 out by amplification of genomic DNA with primers (Table 5) targeting single

540 copy non-homologous regions of $C$. saccharolyticus and $C$. owensensis.

Table 5: PCR primers for C. saccharolyticus and C. owensensis differentiation.

\begin{tabular}{lll}
\hline Species & Primer & Seqeunce \\
\hline C. owensensis & Cowen_F1 & 5' - GGCAAGTGGGAAGAAGATGA - 3' \\
C. owensensis & Cowen_R1 & 5' - CTCCGCAAGACTTGAACACA - 3' \\
C. saccharolyticus & Csacc_F1 & 5' - TATTATGGGGATTGGGACGA - 3' \\
& & \\
C. saccharolyticus & Csacc_R1 & 5' - CTGGCGCACCAAAGATAAAT - 3'
\end{tabular}

549 Sequences were obtained through multiple genome alignment using Mauve 550 (Darling et al., 2004). qPCR reactions were conducted using DreamTaq DNA 551 polymerase (Thermofisher, Waltham, MA, USA) and EvaGreen ${ }^{\circledR}$ Dye (Biotium, 552 Fremont, CA) in a BioRad CFX96 Realtime PCR (BioRad, Herculus, CA, USA) 553 machine. The Quantification cycle $(\mathrm{Cq})$ values and melting curve analysis were 554 determined using the CFX Manager ${ }^{\mathrm{TM}}$ software 3.1 (Bio-Rad, Hercules, CA, 555 USA). The copy numbers obtained in the software by absolute quantification 556 were in relation to defined standard concentrations $(0.02$ to $20 \mathrm{ng} / \mu \mathrm{l})$ obtained 557 from known quantities of genomic DNA obtained from pure cultures. The sum of 
558 calculated copy number values was used to determine the relative population of

559 the different species. The following PCR conditions were used: Denaturation

$56095^{\circ} \mathrm{C} 7 \mathrm{~min} ; 32$ cycles of $95^{\circ} \mathrm{C} 30 \mathrm{~s}, 54^{\circ} \mathrm{C}$ and $56^{\circ} \mathrm{C}$ for $C$. owensensis and $C$

561 saccharolyticus, respectively, for $30 \mathrm{~s}, 70^{\circ} \mathrm{C} 20 \mathrm{~s}$; melting curve analysis: $65^{\circ} \mathrm{C}$

$56230 \mathrm{~s}$ hold time, ramp to $95^{\circ} \mathrm{C}$ with $0.05^{\circ} \mathrm{C} / \mathrm{s}$. Each sample was analysed in

563 biological duplicates.

\section{Mathematical modelling}

566 To quantify and evaluate the effect of the osmotolerant strains, a kinetic

567 mathematical model was adapted from Ljunggren et al. (2011) and run in

568 MATLAB R2017a (Mathworks, USA). The model was set up on a molar basis

569 containing mathematical expressions for microbial growth, substrate

570 consumption, product formation and gas to liquid mass transfer. The model was

571 used with a few alterations to the mass balance equations. The mass balances of

572 the gaseous compounds hydrogen and carbon dioxide are expressed as a change

573 in concentration $(\mathrm{mol} / \mathrm{L})$ over time instead of a change in flow over time. This is

574 similar to what has been described in (Björkmalm et al., 2018) and given as the

575 following equations:

576

$577 \quad \frac{d H_{2, g}}{d t}=\frac{V_{\text {liq }}}{V_{\text {gas }}} * \rho_{t, H_{2}}+\left(-H_{2, g} \cdot \frac{q_{\text {gas }}}{V_{\text {gas }}}\right)$

578

$579 \quad \frac{d \mathrm{CO}_{2, g}}{d t}=\frac{V_{l i q}}{V_{g a s}} * \rho_{t, C O_{2}}+\left(-\mathrm{CO}_{2, g} \cdot \frac{q_{g a s}}{V_{\text {gas }}}\right)$

582 where $\mathrm{V}_{\text {liq }}$ and $\mathrm{V}_{\text {gas }}$ are the liquid and the gas volumes (L), respectively, $\mathrm{q}_{\text {gas }}$ is the

583 total gas flow $(\mathrm{L} / \mathrm{h}), \mathrm{H}_{2, \mathrm{~g}}$ is gaseous hydrogen $(\mathrm{mol} / \mathrm{L}), \mathrm{CO}_{2}$ is gaseous carbon 
584 dioxide $(\mathrm{mol} / \mathrm{L}), \rho_{\mathrm{t}, \mathrm{H} 2}$ and $\rho_{\mathrm{t}, \mathrm{CO} 2}$ are the mass transfer rate of hydrogen and carbon

585 dioxide respectively $(\mathrm{mol} / \mathrm{L} / \mathrm{h})$.

586 The osmolarity expression, Eq 5, is calculated in the same way as Ljunggren et 587 al. (2011), except that $\mathrm{CO}_{2, \text { sol }}$, i.e., the $\mathrm{CO}_{2}$ ionic species (bicarbonate and 588 carbonate), is excluded since these were not measured experimentally. This is 589 further motivated by the fact that, according to model calculations in the current 590 study, $\mathrm{CO}_{2, \text { sol }}$ constituted to less than $2 \%$ of the total osmolarity.

591

592

$$
O S M=G l u+2 \cdot A c+2 \cdot L a c+0.08
$$

593

594 where Glu, Ac and Lac are the concentrations of glucose, acetate and lactate, 595 respectively. 0.08 is the estimated background osmolarity of the medium and it is 596 adjusted slightly in comparison to the benchmark value from Ljunggren et al. 597 (2011). The background osmolarity has not been experimentally measured in this 598 case. The stochiometric factor 2 implies that for each mole of acid produced, one 599 mole of $\mathrm{NaOH}$ is included that was added to maintain the $\mathrm{pH}$.

600 The inhibition due to osmolarity and dissolved hydrogen concentration is 601 expressed as (Ljunggren et al., 2011):

602

603

$$
I_{\text {osm }}=1-\left(\frac{\text { oSM }}{O S M_{\text {crit }}}\right)^{n_{\mu}}
$$

604

605

$$
I_{H_{2, a q}}=1-\left(\frac{H_{2, a q}}{H_{2, a q, c r i t}}\right)^{n_{H_{2}}}
$$

606

607 which are implemented in the growth kinetic equation:

608

$$
\mu=\mu_{\max } \cdot \frac{s}{S+K_{s}} \cdot I_{o s m} \cdot I_{H_{2, a q}}
$$

609 
610 where $n_{\mu}$ and $n_{H 2}$ are exponential parameters describing the degree of inhibition

611 and $\mathrm{OSM}_{\text {crit }}(\mathrm{mol} / \mathrm{L})$ and $\mathrm{H}_{2 \text {,aq,crit }}(\mathrm{mol} / \mathrm{L})$ are the critical osmolarity and critical

612 dissolved hydrogen concentration, respectively. $\mathrm{OSM}_{\text {crit }}$ is central in this context

613 where a high value of $\mathrm{OSM}_{\text {crit }}$ indicates a high tolerance for osmolarity. $\mu\left(\mathrm{h}^{-1}\right)$ is

614 the specific growth rate, $\mu_{\max }\left(\mathrm{h}^{-1}\right)$ is the maximum specific growth rate, $\mathrm{K}_{\mathrm{S}}$

$615(\mathrm{~mol} / \mathrm{L})$ is the affinity constant for glucose and $\mathrm{S}(\mathrm{mol} / \mathrm{L})$ is the concentration of

616 glucose. The mass balance equation for the biomass $\mathrm{X}$ consists of the rate of

617 glucose consumption $\mathrm{r}_{\mathrm{s}}(\mathrm{cmol} / \mathrm{L} / \mathrm{h})$, with $\mathrm{Y}_{\mathrm{S}, \mathrm{X}}(\mathrm{cmol} / \mathrm{mol})$ as the yield of biomass

618 from glucose, and the cell death rate, $r_{c d}\left(h^{-1}\right)$, which is based on first-order

619 kinetics.

620 The model was evaluated against different batch experimental data. To fit the

621 model to experimental data a parameter calibration was conducted using the

622 function lsqcurvefit in MATLAB. This function solves the nonlinear curve-fitting

623 problem using the least-square method. The parameters considered to be of

624 greatest importance were $\mu_{\max }, \mathrm{OSM}_{\text {crit }}, \mathrm{r}_{\mathrm{cd}}, \mathrm{Y}_{\mathrm{S}, \mathrm{H} 2}\left(\mathrm{H}_{2}\right.$ yield coefficient, mol

$625 \mathrm{H}_{2} /$ mol glucose), $\mathrm{n}_{\mu}$ and $\mathrm{n}_{\mathrm{H} 2}$. The MATLAB function nlparci was used to

626 calculate the $95 \%$ confidence interval for the calibrated parameters to assess their

627 uncertainties.

628 To assess the accuracy of the model in relation to the experimental data, $\mathrm{R}^{2}$

629 values and curve slope values were calculated. This was done by plotting the

630 simulated values against the experimental values followed by a linear regression

631 which gave the $\mathrm{R}^{2}$ value as well as the linear equation $\mathrm{y}=\mathrm{k} \cdot \mathrm{x}$, where $\mathrm{k}$ is the

632 curve slope value.

633 The biomass yield coefficient $\mathrm{Y}_{\mathrm{S}, \mathrm{X}}$ was calculated using the experimental data but

634 altered in the $80 \mathrm{~g} / \mathrm{L}$ model to fit the experimental data. The yields for hydrogen,

635 acetate, lactate and carbon dioxide used in the model, $\mathrm{Y}_{\mathrm{S}, \mathrm{H} 2}, \mathrm{Y}_{\mathrm{S}, \mathrm{Ac}}, \mathrm{Y}_{\mathrm{S}, \mathrm{Lac}}$ and

$636 \mathrm{Y}_{\mathrm{S}, \mathrm{CO} 2}$, were based on stoichiometry according to:

637 
Declarations

646 Not applicable

647 Ethics approval and consent to participate

648 Not applicable

\section{Consent for publication}

650 Not applicable.

\section{Availability of data and materials}

652 All data generated or analyzed during this study are included in this article. If

653 additional information is needed, please contact the corresponding author.

\section{Competing interests}

655 The authors declare that they have no competing interests.

\section{Funding}

657 This study was funded by the Swedish Energy Agency (Metanova project no 658 31090-2), Formas (HighQH2, 2017-00795) and Vinnova (Multibio, 2017-03286)

$659-$ Sweden's Innovation Agency of which neither participated in the execution of 660 the study or in the manuscript writing.

661 Authors' contributions

662 EB: design, operation and supervision fermentation processes, metabolite 663 analysis and manuscript writing.

664 JB: data analysis, calculations, model development and manuscript writing.

665 JPB: fermentation processes, metabolite analysis and manuscript review

666 KS: development of genetic protocol and manuscript review. 
667 KW: supervision of modelling, analysis and fermentation and manuscript 668 writing.

669 EvN: supervision of fermentation processes, modelling, analysis and manuscript

670 writing.

\section{Corresponding author}

Correspondence to ed.van_niel@tmb.lth.se

\section{Author details}

Current address EB: Ballintober, Hollywood, Co. Wicklow, W91 RDP3, Ireland and JPB: Coriolis Pharma Research GmbH, Fraunhoferstrasse 18B, 82152 Planegg, Germany.

\section{Acknowledgements}

The authors are grateful to the 3 Swedish funding agencies, Swedish Energy Agency, Formas and Vinnova for funding this research.

\section{References}

Azimian, L., Bassi, A., Mercer, S.M. 2019. Investigation of growth kinetics of Debaryomyces hansenii (LAF-3 $10 \mathrm{U}$ ) in petroleum refinery desalter effluent. The Canadian Journal of Chemical Engineering, 97(1), 27-31.

Azwar, M.Y., Hussain, M.A., Abdul-Wahab, A.K. 2014. Development of biohydrogen production by photobiological, fermentation and electrochemical processes: A review. Renewable and Sustainable Energy Reviews, 31, 158-173.

Björkmalm, J., Byrne, E., van Niel, E.W.J., Willquist, K. 2018. A non-linear model of hydrogen production by Caldicellulosiruptor saccharolyticus for diauxic-like consumption of lignocellulosic sugar mixtures. Biotechnology for Biofuels, 11(1), 175.

Byrne, E., Kovacs, K., van Niel, E.W.J., Willquist, K., Svensson, S.-E., Kreuger, E. 2018. Reduced use of phosphorus and water in sequential dark fermentation and anaerobic digestion of wheat straw and the application of ensiled steampretreated lucerne as a macronutrient provider in anaerobic digestion. Biotechnology for Biofuels, 11(1), 281.

Ciranna, A., Ferrari, R., Santala, V., Karp, M. 2014. Inhibitory effects of substrate and soluble end products on biohydrogen production of the alkalithermophile Caloramator celer: Kinetic, metabolic and transcription analyses. International Journal of Hydrogen Energy, 39(12), 6391-6401.

Claassen, P.A.M., van Lier, J.B., Lopez Contreras, A.M., van Niel, E.W.J., Sijtsma, L., Stams, A.J.M., de Vries, S.S., Weusthuis, R.A. 1999. Utilisation of biomass for the supply of energy carriers. Applied Microbiology and Biotechnology, 52(6), 741-755. 
Darling, A.C.E., Mau, B., Blattner, F.R., Perna, N.T. 2004. Mauve: multiple alignment of conserved genomic sequence with rearrangements. Genome research, 14(7), 1394-1403.

de Vrije, T., Bakker, R.R., Budde, M.A., Lai, M.H., Mars, A.E., Claassen, P.A. 2009. Efficient hydrogen production from the lignocellulosic energy crop Miscanthus by the extreme thermophilic bacteria Caldicellulosiruptor saccharolyticus and Thermotoga neapolitana. Biotechnology for Biofuels, 2(1), 12.

de Vrije, T., Mars, A.E., Budde, M.A.W., Lai, M.H., Dijkema, C., de Waard, P., Claassen, P.A.M. 2007. Glycolytic pathway and hydrogen yield studies of the extreme thermophile Caldicellulosiruptor saccharolyticus. Applied Microbiology and Biotechnology, 74(6), 1358.

Dötsch, A., Severin, J., Alt, W., Galinski, E.A., Kreft, J.-U. 2008. A mathematical model for growth and osmoregulation in halophilic bacteria. Microbiology, 154(10), 2956-2969.

Dragosits, M., Mattanovich, D. 2013. Adaptive laboratory evolution - principles and applications for biotechnology. Microbial Cell Factories, 12(1), 64.

European Parliament and Council. 2015. Directive (EU) 2015/1513 of the European parliament and of the council of 9 September 2015 amending Directive 98/70/EC relating to the quality of petrol and diesel fuels and amending Directive 2009/28/EC on the promotion of the use of energy from renewable sources, Official Journal of the European Union.

Foglia, D., Ljunggren, M., Wukovits, W., Friedl, A., Zacchi, G., Urbaniec, K., Markowski, M. 2010. Integration studies on a two-stage fermentation process for the production of biohydrogen. Journal of Cleaner Production, 18, S72-S80.

Gonçalves, L.G., Borges, N., Serra, F., Fernandes, P.L., Dopazo, H., Santos, H. 2012. Evolution of the biosynthesis of di-myo-inositol phosphate, a marker of adaptation to hot marine environments. Environmental Microbiology, 14(3), 691-701.

Kempf, B., Bremer, E. 1998. Uptake and synthesis of compatible solutes as microbial stress responses to high-osmolality environments. Arch Microbiol, 170(5), 31930.

Ljunggren, M., Willquist, K., Zacchi, G., van Niel, E.W. 2011. A kinetic model for quantitative evaluation of the effect of hydrogen and osmolarity on hydrogen production by Caldicellulosiruptor saccharolyticus. Biotechnology for Biofuels, 4(1), 31 .

Ljunggren, M., Zacchi, G. 2010. Techno-economic analysis of a two-step biological process producing hydrogen and methane. Bioresource Technology, 101(20), 7780-7788.

Martins, L.O., Santos, H. 1995. Accumulation of Mannosylglycerate and Di-myoInositol-Phosphate by Pyrococcus furiosus in Response to Salinity and Temperature. Applied and Environmental Microbiology, 61(9), 3299-3303.

Nunes, O.C., Manaia, C.M., Da Costa, M.S., Santos, H. 1995. Compatible Solutes in the Thermophilic Bacteria Rhodothermus marinus and "Thermus thermophilus". Applied and Environmental Microbiology, 61(6), 2351-2357.

Panagiotopoulos, I.A., Bakker, R.R., de Vrije, T., Koukios, E.G., Claassen, P.A.M. 2010. Pretreatment of sweet sorghum bagasse for hydrogen production by 
Pawar, S.S. 2014. Caldicellulosiruptor saccharolyticus: an Ideal Hydrogen Producer? in: Faculty of Engineering, LTH, Vol. PhD Thesis, Lund University. Lund.

Pawar, S.S., Nkemka, V.N., Zeidan, A.A., Murto, M., van Niel, E.W.J. 2013. Biohydrogen production from wheat straw hydrolysate using Caldicellulosiruptor saccharolyticus followed by biogas production in a twostep uncoupled process. International Journal of Hydrogen Energy, 38(22), 9121-9130.

Pawar, S.S., van Niel, E.W.J. 2014. Evaluation of assimilatory sulphur metabolism in Caldicellulosiruptor saccharolyticus. Bioresource Technology, 169, 677-685.

Pawar, S.S., Vongkumpeang, T., Grey, C., van Niel, E.W. 2015. Biofilm formation by designed co-cultures of Caldicellulosiruptor species as a means to improve hydrogen productivity. Biotechnology for Biofuels, 8(1), 19.

Peabody, G., Winkler, J., Fountain, W., Castro, D.A., Leiva-Aravena, E., Kao, K.C. 2016. Benefits of a Recombination-Proficient Escherichia coli System for Adaptive Laboratory Evolution. Applied and environmental microbiology, 82(22), 6736-6747.

Peintner, C., Zeidan, A.A., Schnitzhofer, W. 2010. Bioreactor systems for thermophilic fermentative hydrogen production: evaluation and comparison of appropriate systems. Journal of Cleaner Production, 18, S15-S22.

Rainey, F.A., Donnison, A.M., Janssen, P.H., Saul, D., Rodrigo, A., Bergquist, P.L., Daniel, R.M., Stackebrandt, E., Morgan, H.W. 1994. Description of Caldicellulosiruptor saccharolyticus gen. nov., sp. nov: An obligately anaerobic, extremely thermophilic, cellulolytic bacterium. FEMS Microbiology Letters, 120(3), 263-266.

Rodrigues, M.V., Borges, N., Almeida, C.P., Lamosa, P., Santos, H. 2009. A Unique $\beta-$ 1,2-Mannosyltransferase of Thermotoga maritima That Uses Di-myo-Inositol Phosphate as the Mannosyl Acceptor. Journal of Bacteriology, 191(19), 61056115.

Sander, K.B., Chung, D., Klingeman, D.M., Giannone, R.J., Rodriguez, M., Whitham, J., Hettich, R.L., Davison, B.H., Westpheling, J., Brown, S.D. 2020. Gene targets for engineering osmotolerance in Caldicellulosiruptor bescii. Biotechnology for Biofuels, 13(1), 50 .

Sanderson, K. 2011. Lignocellulose: A chewy problem. Nature, 474, S12.

Schleifer, K.-H. 2009. Phylum XIII. Firmicutes Gibbons and Murray 1978, 5 (Firmacutes [sic] Gibbons and Murray 1978, 5). in: Bergey's Manual ${ }^{\circledR}$ of Systematic Bacteriology, Springer, pp. 19-1317.

Sims, R., Taylor, M., Saddler, J., Mabee, W. 2008. From 1st-to 2nd-generation biofuel technologies. Paris: International Energy Agency (IEA) and Organisation for Economic Co-Operation and Development.

Sivakumar, A., Srinivasaraghavan, T., Swaminathan, T., Baradarajan, A. 1994. Extended monod kinetics for substrate inhibited systems. Bioprocess Engineering, 11(5), 185-188.

Tomás, A.F., Karakashev, D., Angelidaki, I. 2013. Thermoanaerobacter pentosaceus sp. nov., an anaerobic, extremely thermophilic, high ethanol-yielding bacterium 
isolated from household waste. International Journal of Systematic and Evolutionary Microbiology, 63(7), 2396-2404. van Niel, E.W.J., Claassen, P.A.M., Stams, A.J.M. 2003. Substrate and product inhibition of hydrogen production by the extreme thermophile, Caldicellulosiruptor saccharolyticus. Biotechnol Bioeng, $\mathbf{8 1}$.

VanFossen, A.L., Verhaart, M.R.A., Kengen, S.M.W., Kelly, R.M. 2009. Carbohydrate Utilization Patterns for the Extremely Thermophilic Bacterium Caldicellulosiruptor saccharolyticus Reveal Broad Growth Substrate Preferences. Applied and Environmental Microbiology, 75(24), 7718-7724.

Willquist, K., Claassen, P.A.M., van Niel, E.W.J. 2009. Evaluation of the influence of $\mathrm{CO}_{2}$ on hydrogen production by Caldicellulosiruptor saccharolyticus. International Journal of Hydrogen Energy, 34(11), 4718-4726.

Zeidan, A.A., van Niel, E.W.J. 2010. A quantitative analysis of hydrogen production efficiency of the extreme thermophile Caldicellulosiruptor owensensis OLT. International Journal of Hydrogen Energy, 35(3), 1128-1137. 
821 Figure 1. Development of osmotolerant strains of $C$. owensensis, $C$.

822 kronotskyensis, C. bescii, C. acetigenus and C. kristjanssonii. Values in

823 green indicate osmotolerant adaptation steps were completed on stated

824 concentrations of glucose. Values in yellow indicate the final osmotolerant

825 development step and therefore the highest concentration of glucose that

826 the strains can be grown.

828 Figure 2. Experimental data (discrete points) and modelling results (lines)

829 for the $10 \mathrm{~g} / \mathrm{L}$ glucose cultures. Upper left: glucose consumption, acetate

830 and lactate production. Upper right: biomass production. Lower left:

831 hydrogen productivity. Lower right: accumulated hydrogen production.

833 Figure 3. Experimental data (discrete points) and modelling results (lines)

834 for the $30 \mathrm{~g} / \mathrm{L}$ glucose cultures. Upper left: glucose consumption, acetate

835 and lactate production. Upper right: biomass production. Lower left:

836 hydrogen productivity. Lower right: accumulated hydrogen production.

838 Figure 4. Experimental data (discrete points) and modelling results (lines)

839 for the $80 \mathrm{~g} / \mathrm{L}$ glucose cultures. Upper left: glucose consumption, acetate

840 and lactate production. Upper right: biomass production. Lower left:

841 hydrogen productivity. Lower right: accumulated hydrogen production.

843 Figure 5. Comparison of the calibrated parameters OSM $_{\text {crit }}$ (orange) and

$844 \quad \mathrm{~K}_{\mathrm{s}}$ (grey).

846 Figure 6. Simulated values of $\mathrm{I}_{\mathrm{osm}}$ and $\mathrm{I}_{\mathrm{H} 2 \text {,aq }}$ for the different models. 
Figure 1

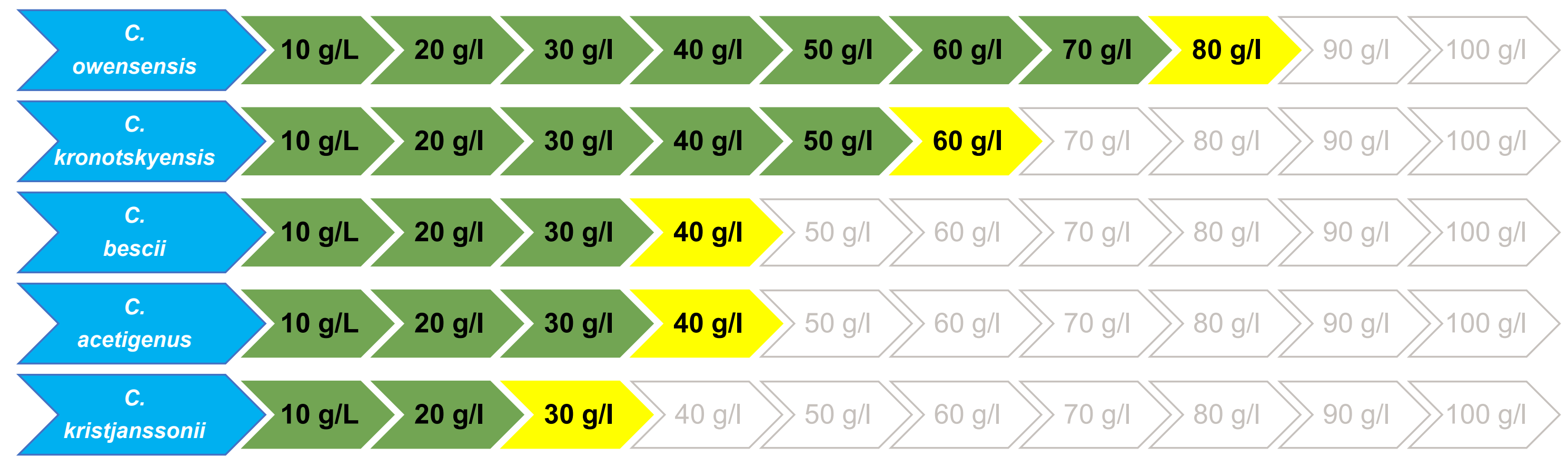


Figure 2
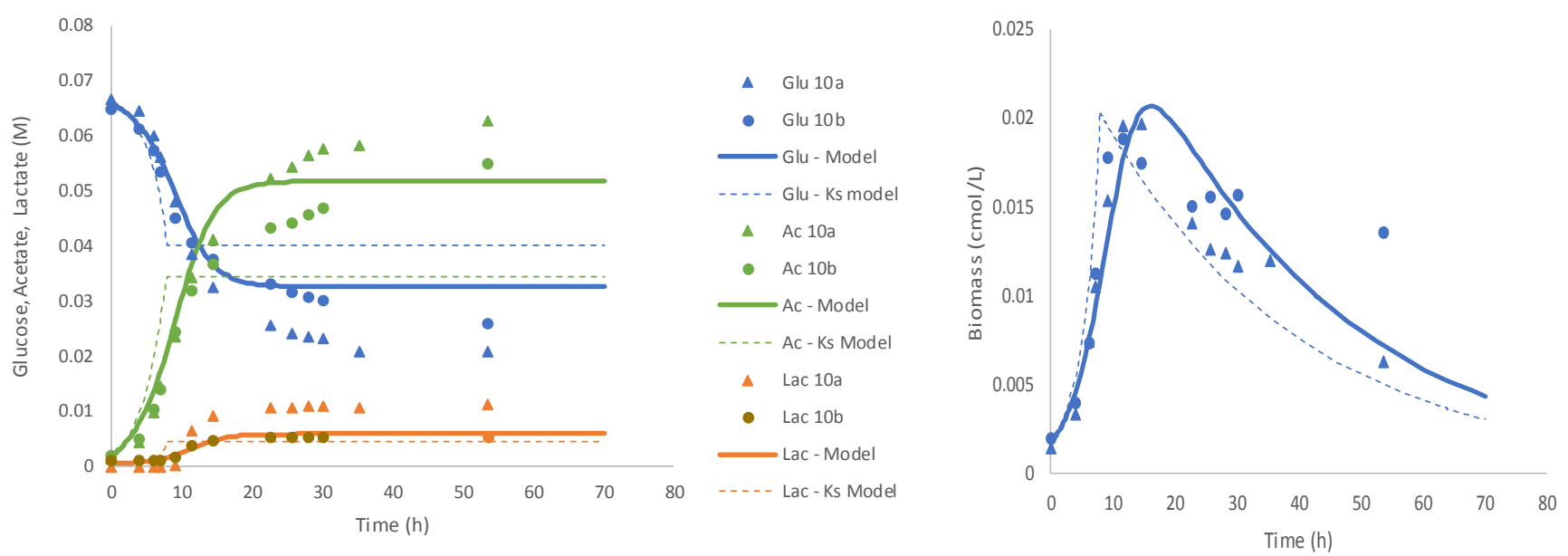

- Biomass 10a

- Biomass $10 \mathrm{~b}$

Biomass - Model

. . - . - Biomass - Ks Mode

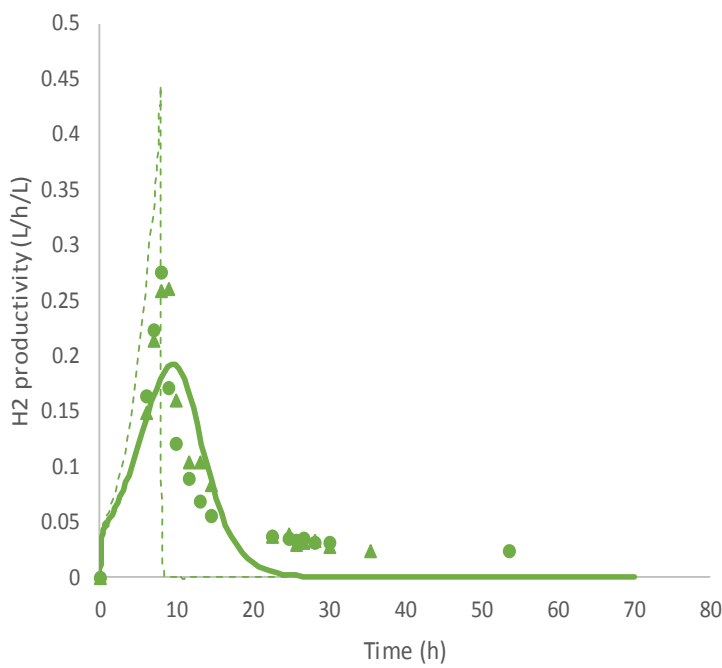

4 H2 prod. 10a

- H2 prod. $10 \mathrm{~b}$

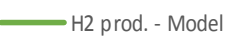

- . - H2 prod. - Ks Mode

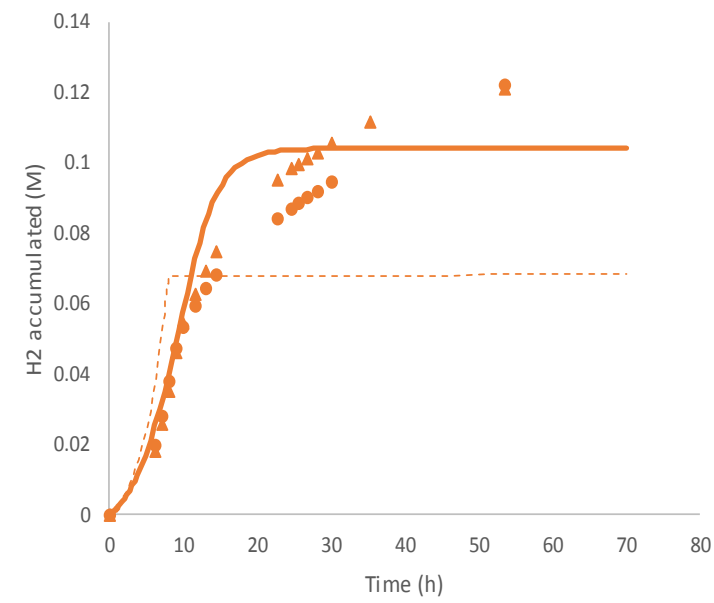

H2 acc. 10

- H2 acc. $10 \mathrm{~b}$

H2 acc. - Model H2 acc. - Ks Model 
Figure 3
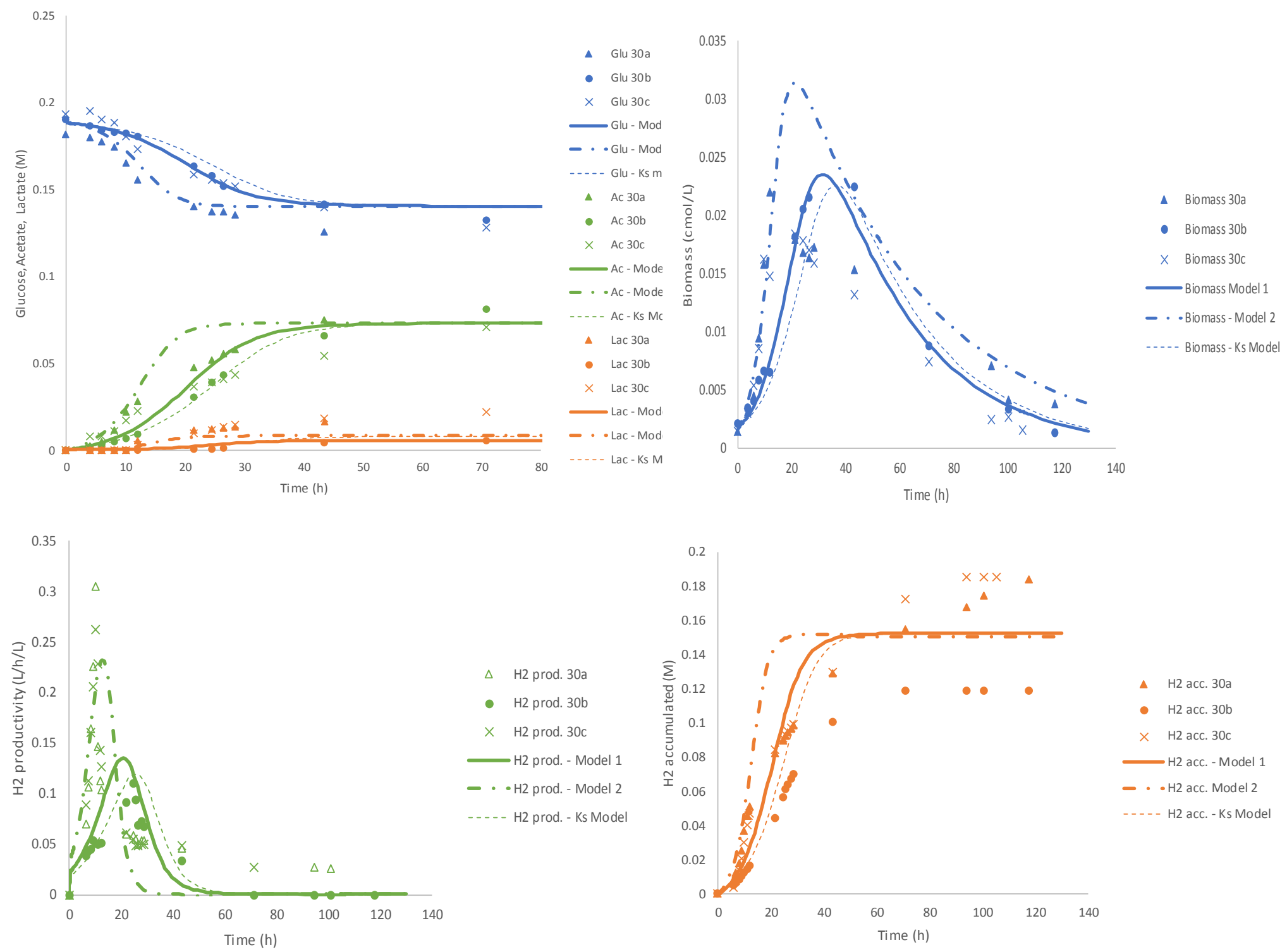

Figure 4
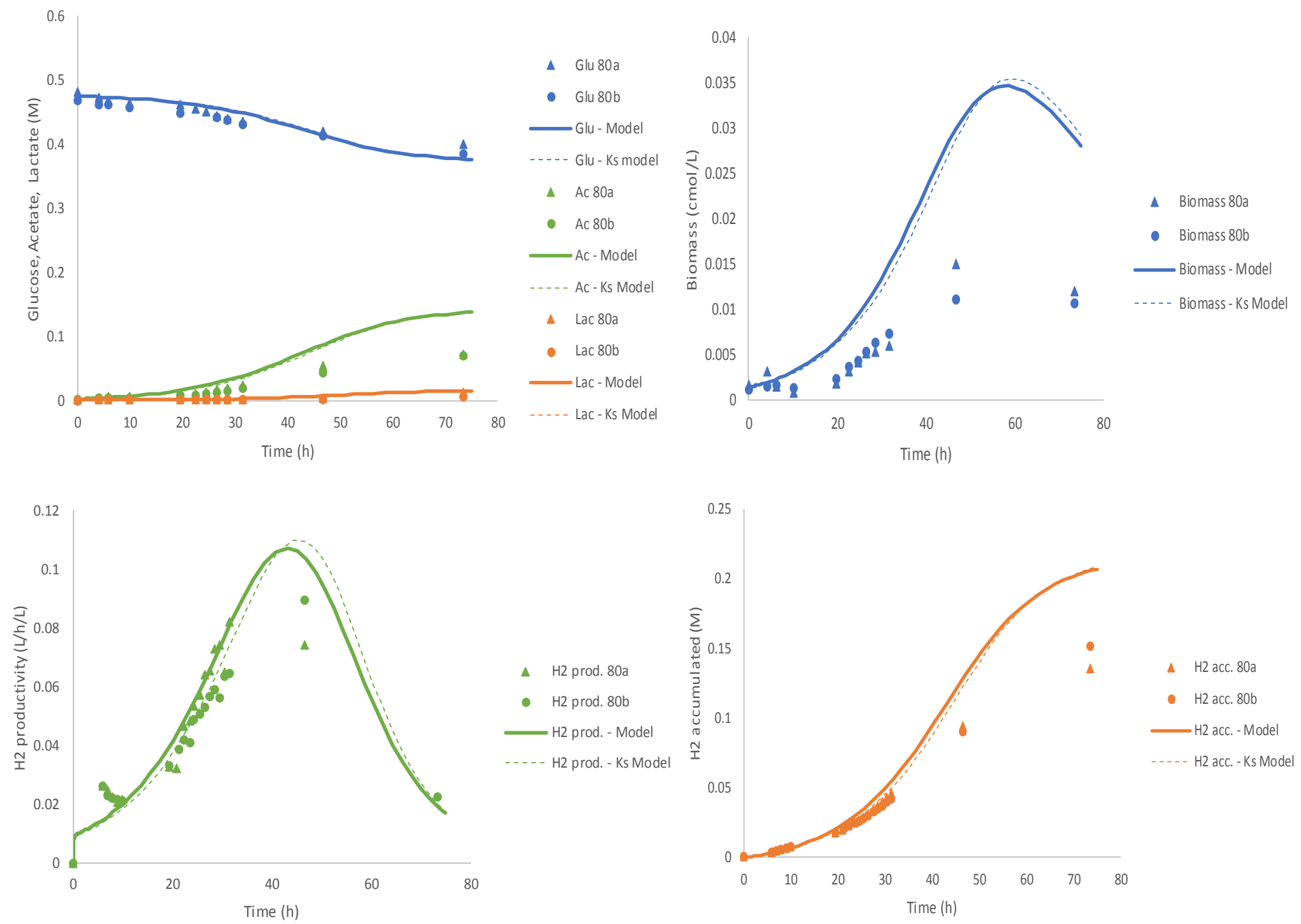


\section{Figure 5}

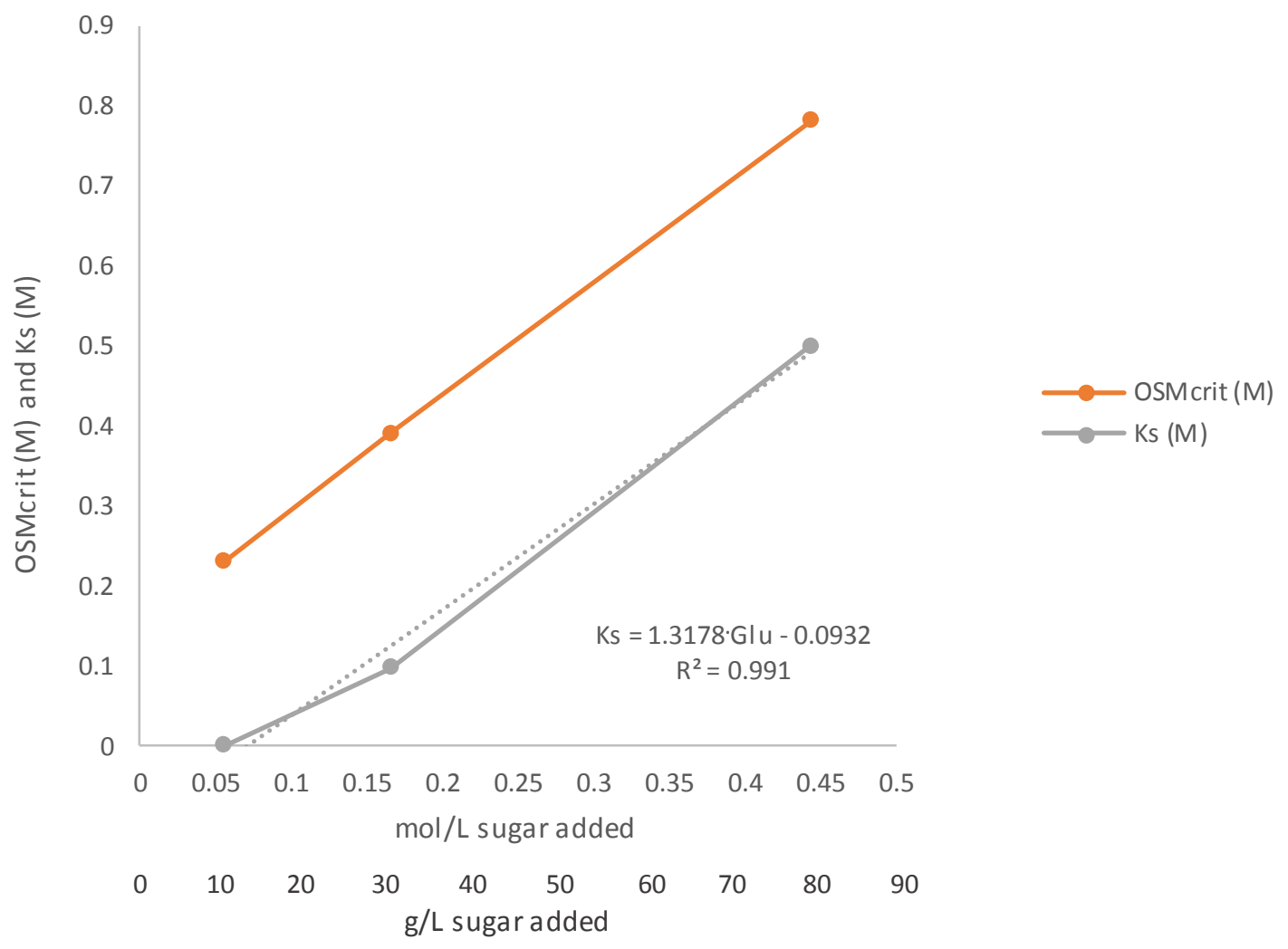


Figure 6
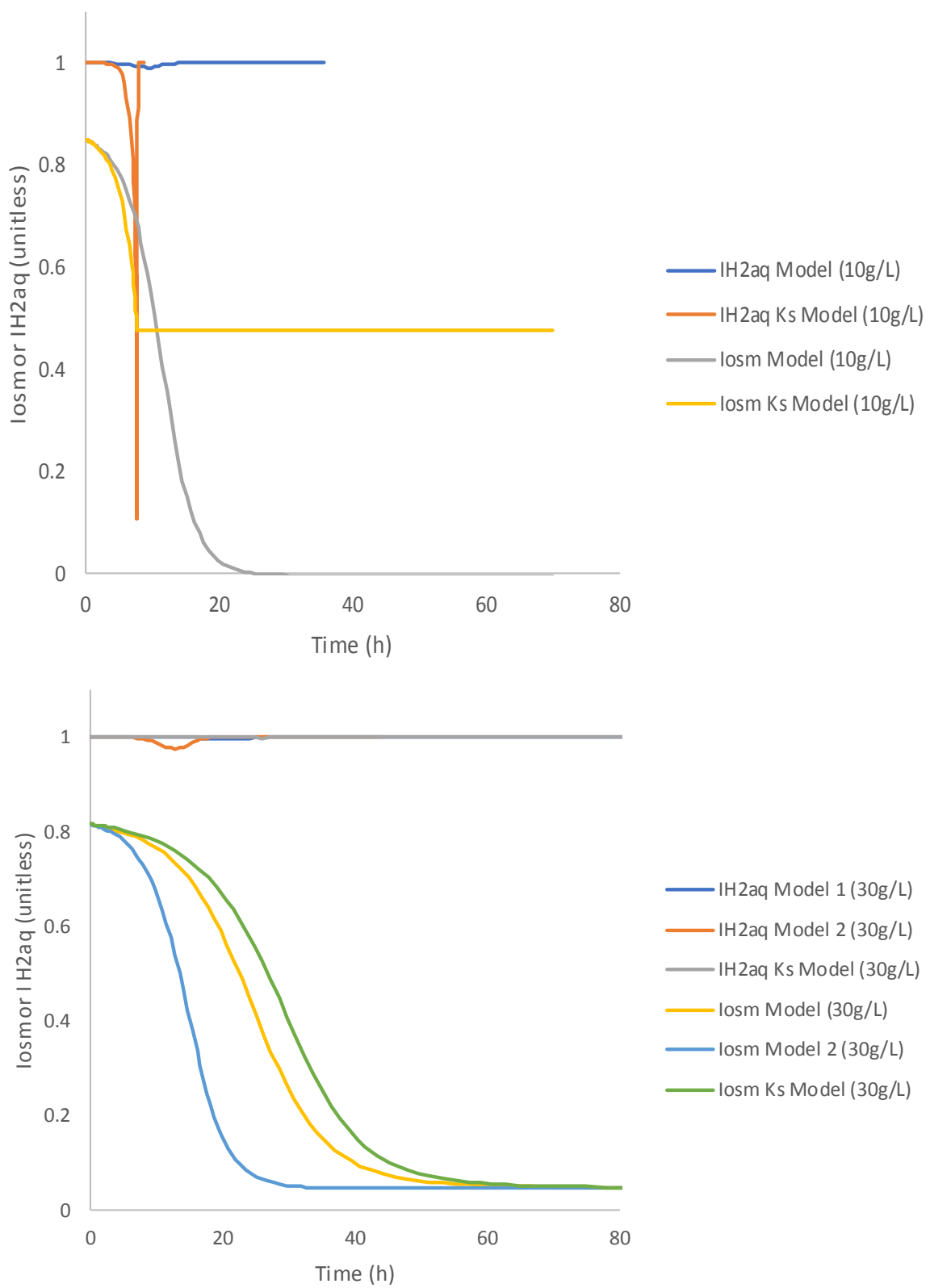

— IH2aq Model 1 (30g/L)

— IH2aq Model $2(30 \mathrm{~g} / \mathrm{L})$

—IH2aq Ks Model (30g/L)

— losm Model (30g/L)

— losm Model 2 (30g/L)

— losm Ks Model (30g/L)

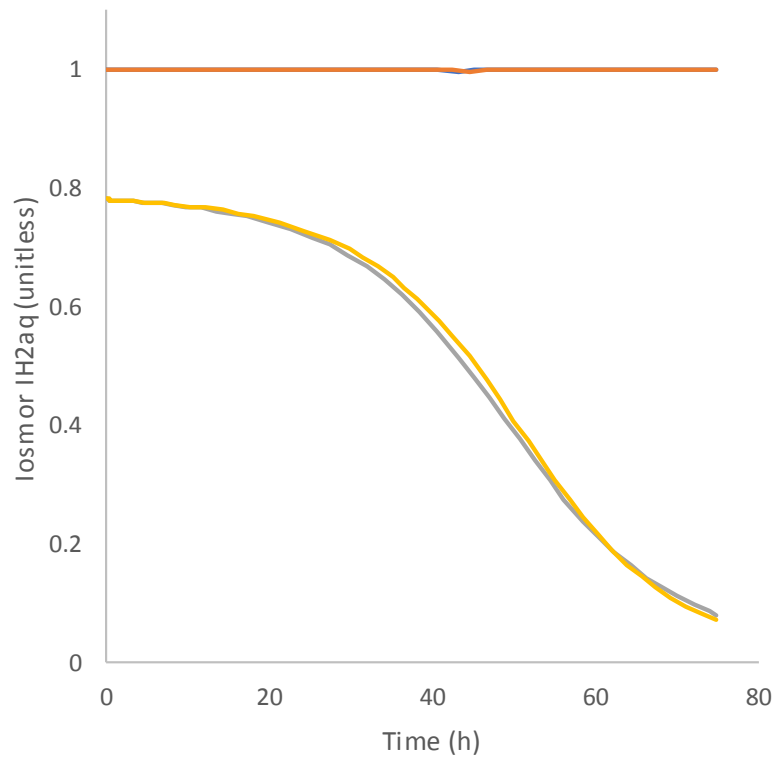

— IH2aq Model (80g/L)

—IH2aq Ks Model (80g/L)

— losm Model (80g/L)

— losm Ks Model (80g/L) 
Figures

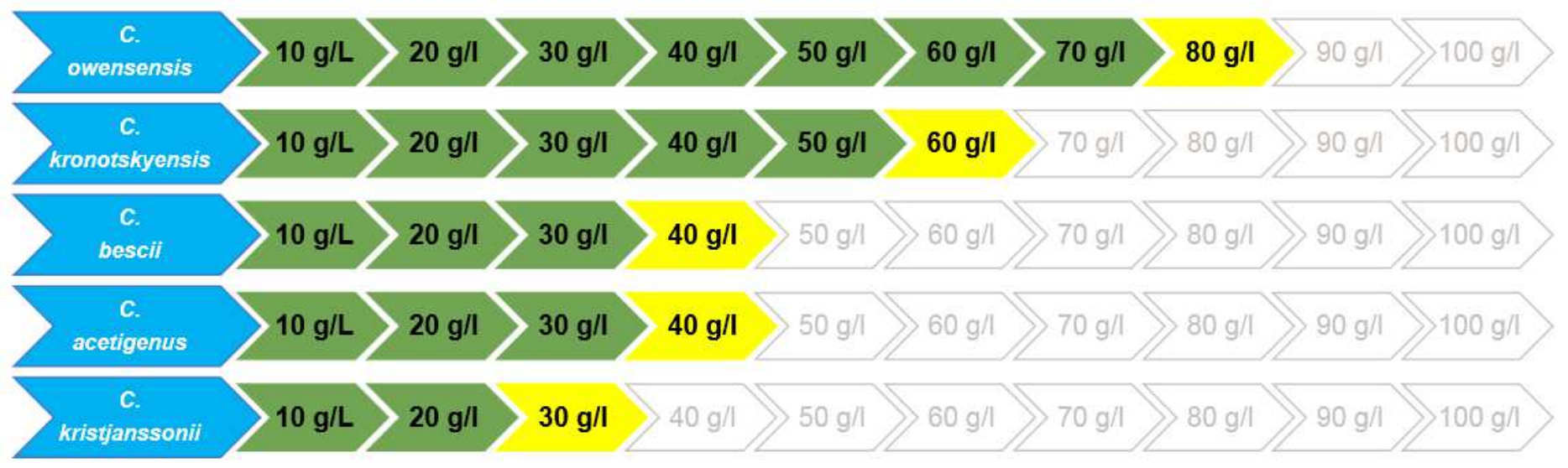

\section{Figure 1}

Development of osmotolerant strains of C. owensensis, C. kronotskyensis, C. bescii, C. acetigenus and C. kristjanssonii. Values in green indicate osmotolerant adaptation steps were completed on stated concentrations of glucose. Values in yellow indicate the final osmotolerant development step and therefore the highest concentration of glucose that the strains can be grown.
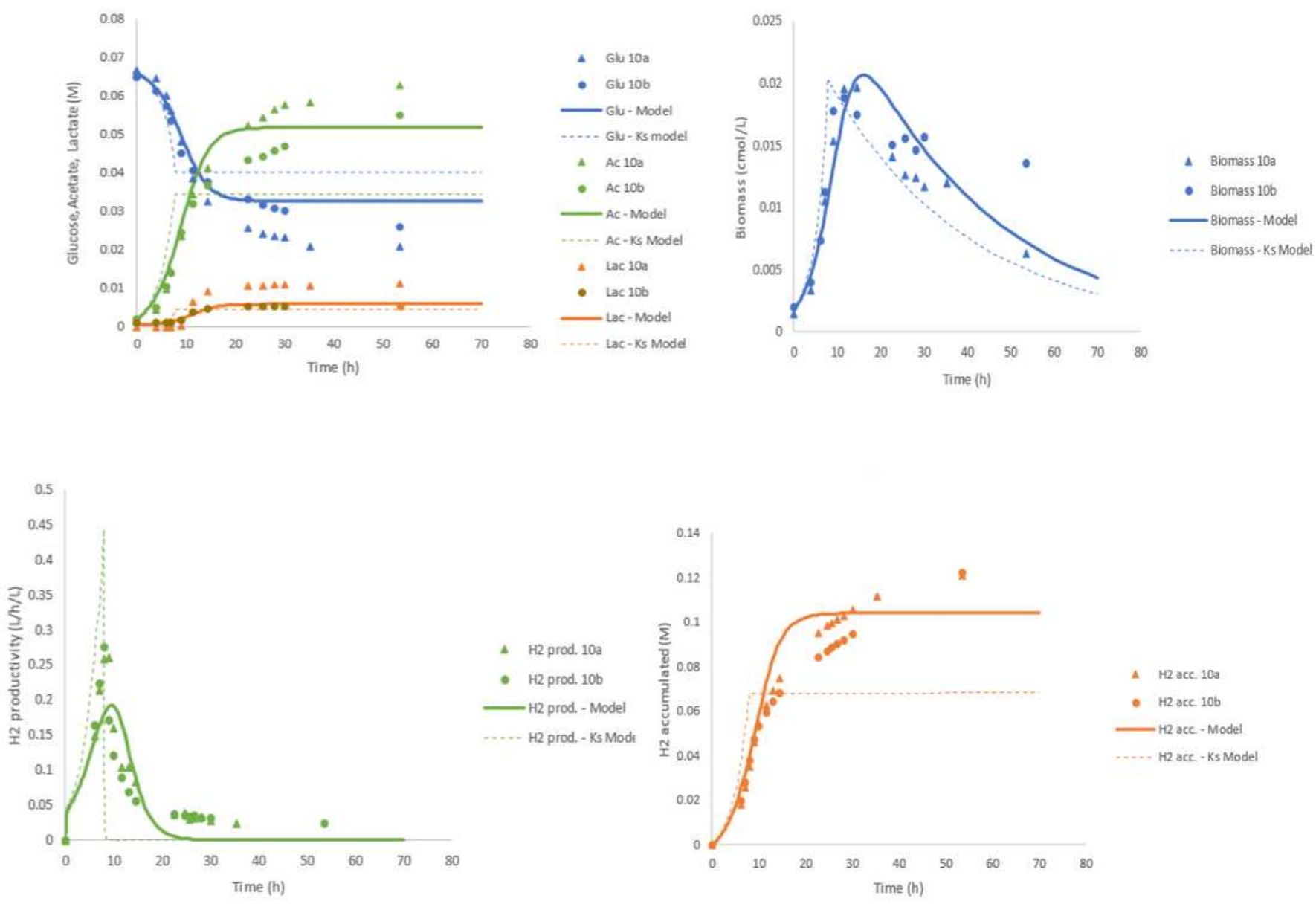
Figure 2

Experimental data (discrete points) and modelling results (lines) for the $10 \mathrm{~g} / \mathrm{L}$ glucose cultures. Upper left: glucose consumption, acetate and lactate production. Upper right: biomass production. Lower left: hydrogen productivity. Lower right: accumulated hydrogen production.
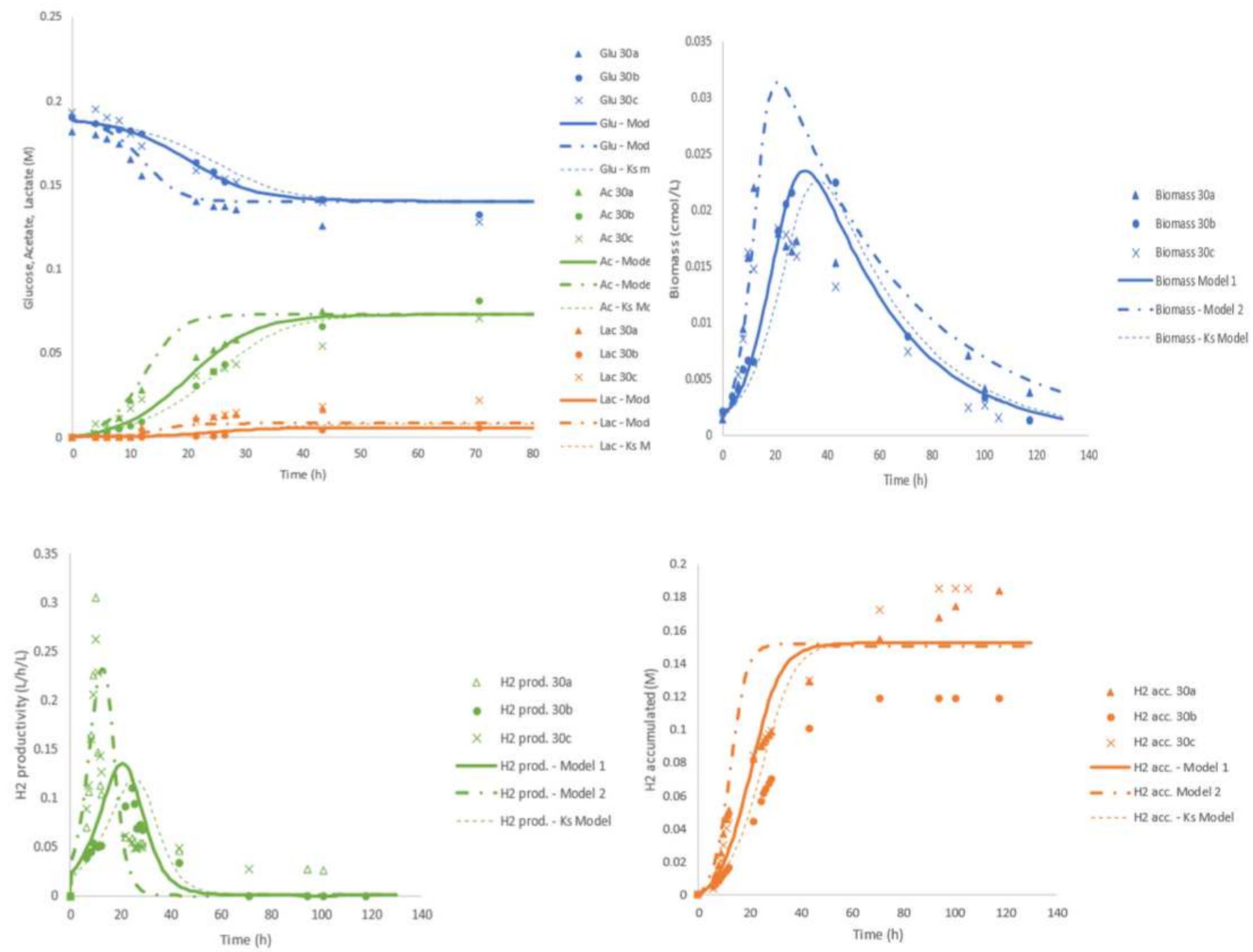

\section{Figure 3}

Experimental data (discrete points) and modelling results (lines) for the $30 \mathrm{~g} / \mathrm{L}$ glucose cultures. Upper left: glucose consumption, acetate and lactate production. Upper right: biomass production. Lower left: hydrogen productivity. Lower right: accumulated hydrogen production. 

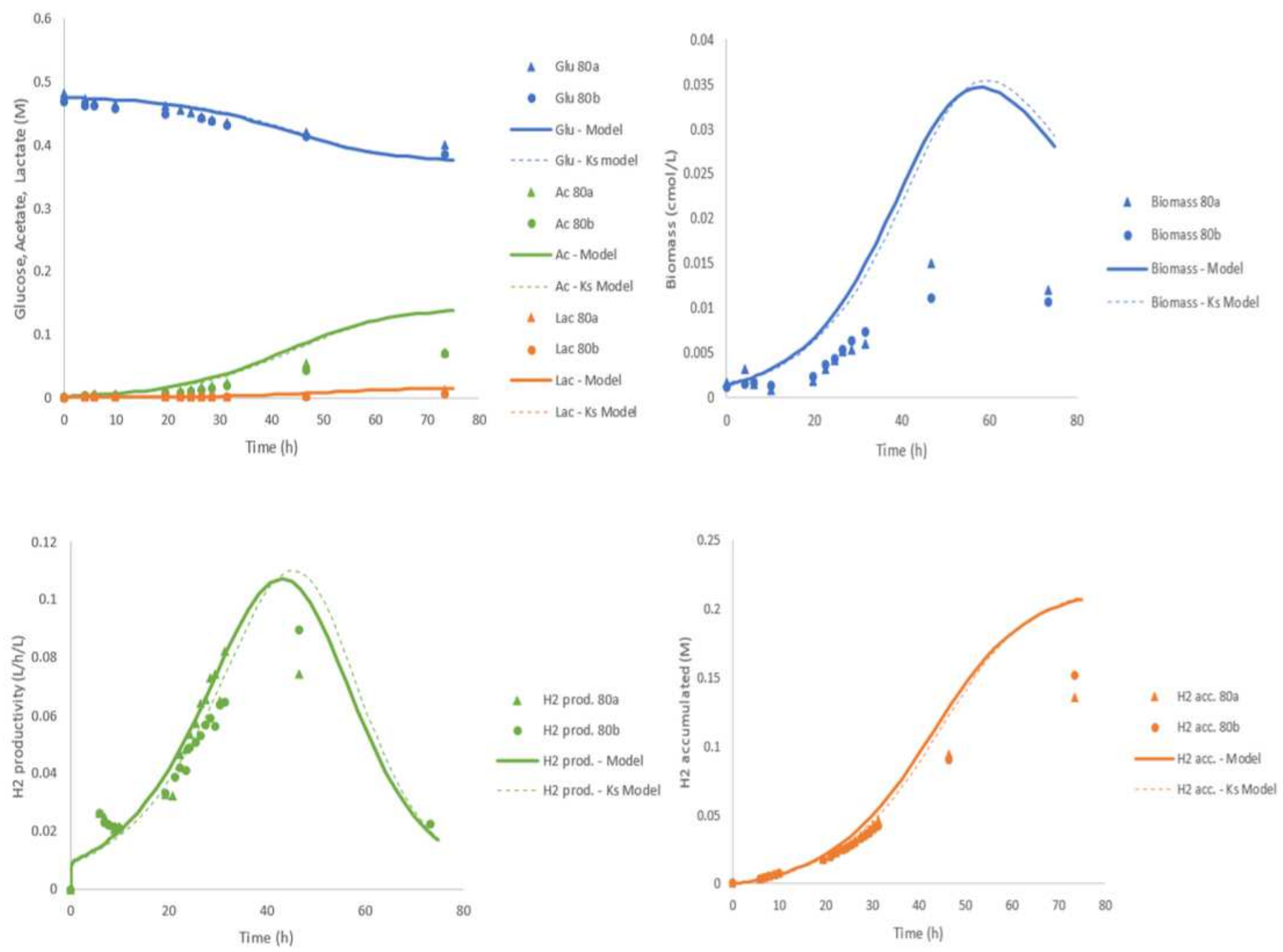

\section{Figure 4}

Experimental data (discrete points) and modelling results (lines) for the $80 \mathrm{~g} / \mathrm{L}$ glucose cultures. Upper left: glucose consumption, acetate and lactate production. Upper right: biomass production. Lower left: hydrogen productivity. Lower right: accumulated hydrogen production. 


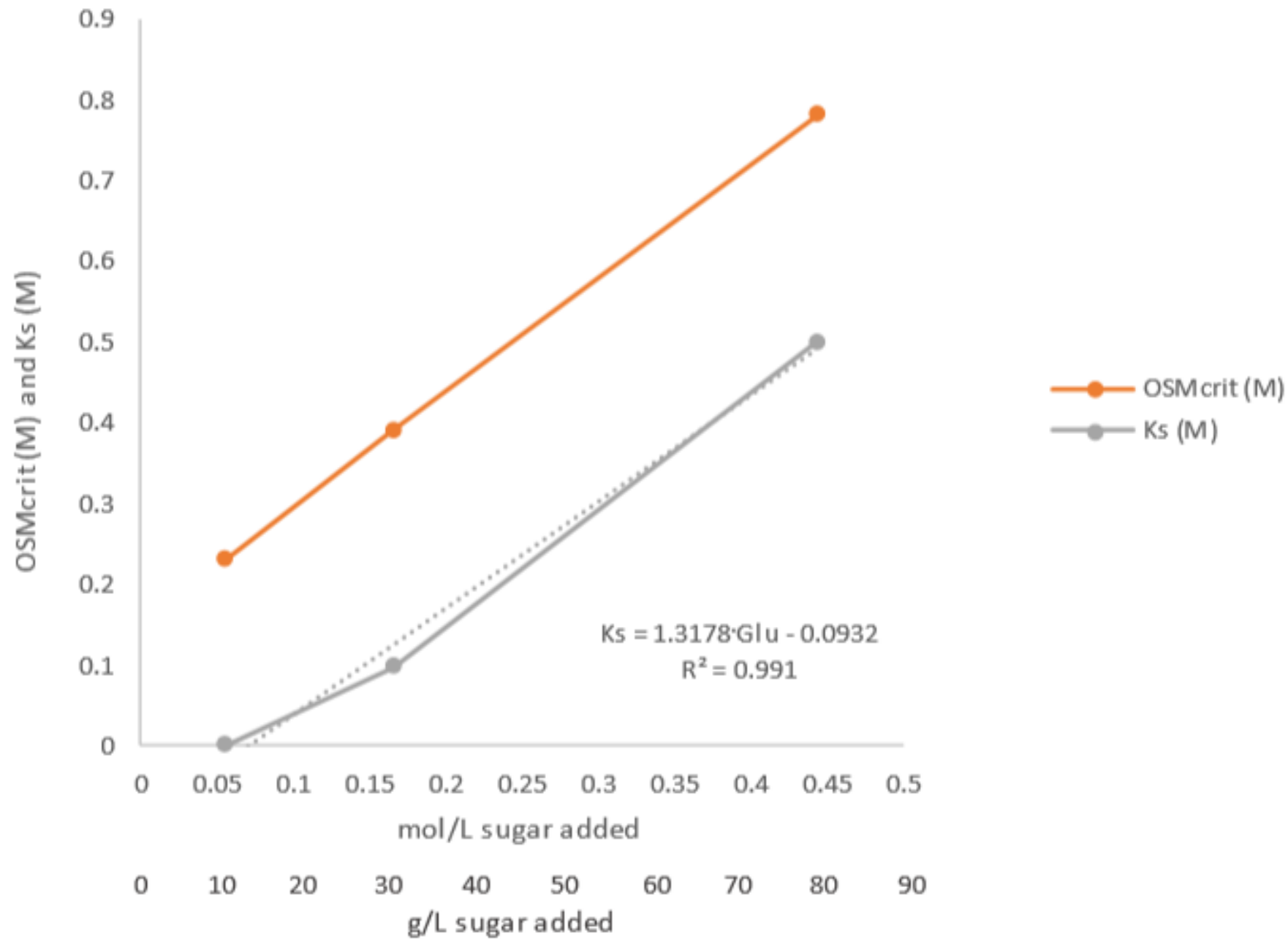

Figure 5

Comparison of the calibrated parameters OSMcrit (orange) and Ks (grey).
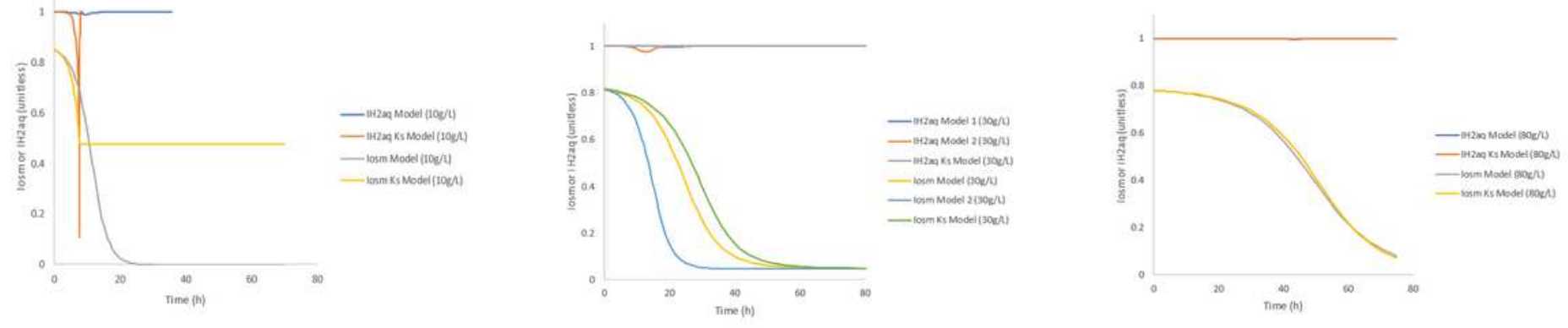

Figure 6

Simulated values of losm and $\mathrm{IH}$,aq for the different models 